\title{
EUV Lithography: From the Very Beginning to the Eve of Manufacturing
}

\section{Anthony Yen}

Anthony Yen, "EUV Lithography: From the Very Beginning to the Eve of Manufacturing," Proc. SPIE 9776, Extreme Ultraviolet (EUV) Lithography VII, 977632 (16 June 2016); doi: 10.1117/12.2236044

SPIE. Event: SPIE Advanced Lithography, 2016, San Jose, California, United States 


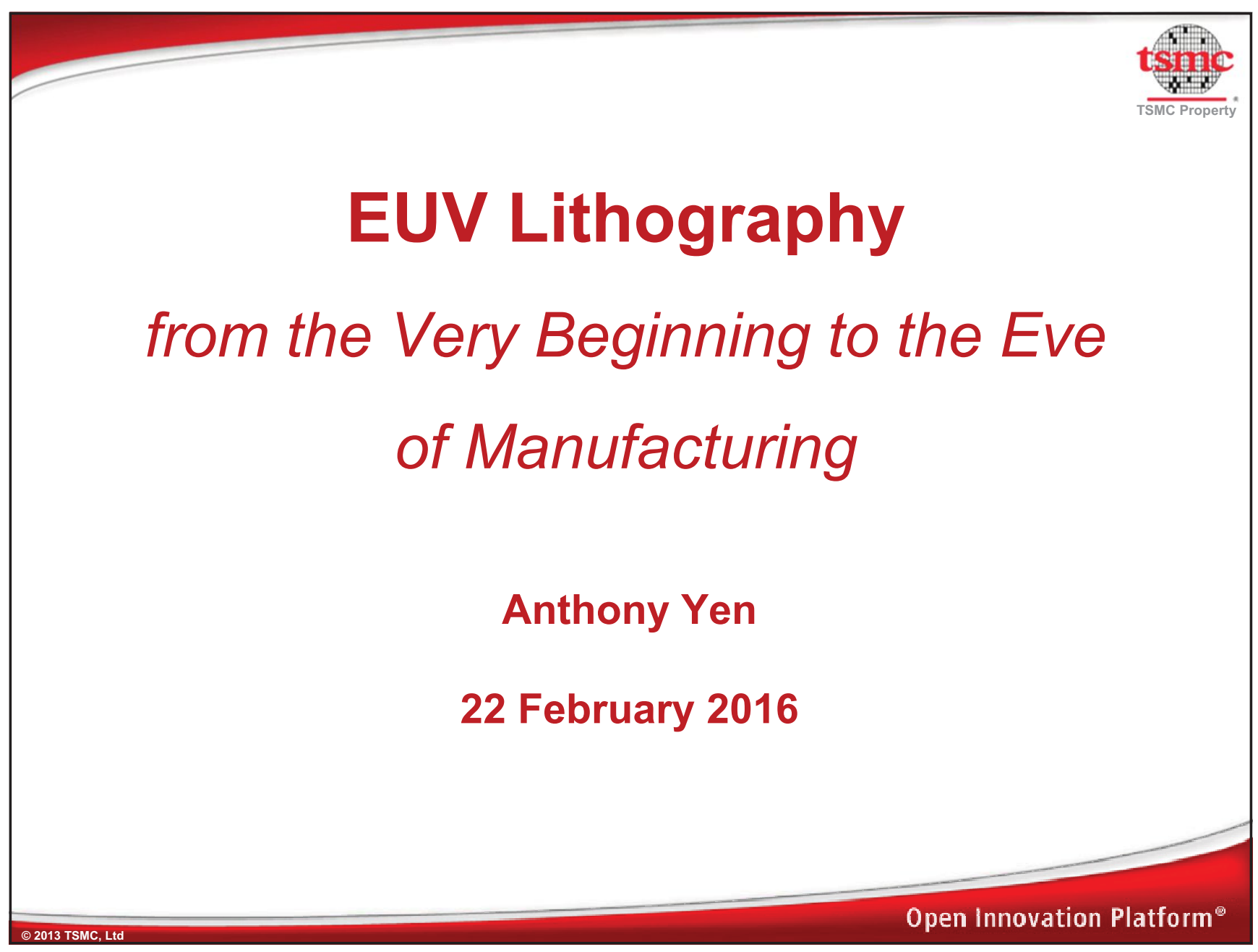

Extreme Ultraviolet (EUV) Lithography VII, edited by Eric M. Panning, Kenneth A. Goldberg. Proc. of SPIE Vol. 9776, 977632 - ( 2016 SPIE · CCC code: 0277-786X/16/\$18 · doi: 10.1117/12.2236044

Proc. of SPIE Vol. $9776977632-1$

Downloaded From: https://www.spiedigitallibrary.org/conference-proceedings-of-spie on $26 \mathrm{Apr} 2023$ Terms of Use: https://www.spiedigitallibrary.org/terms-of-use 


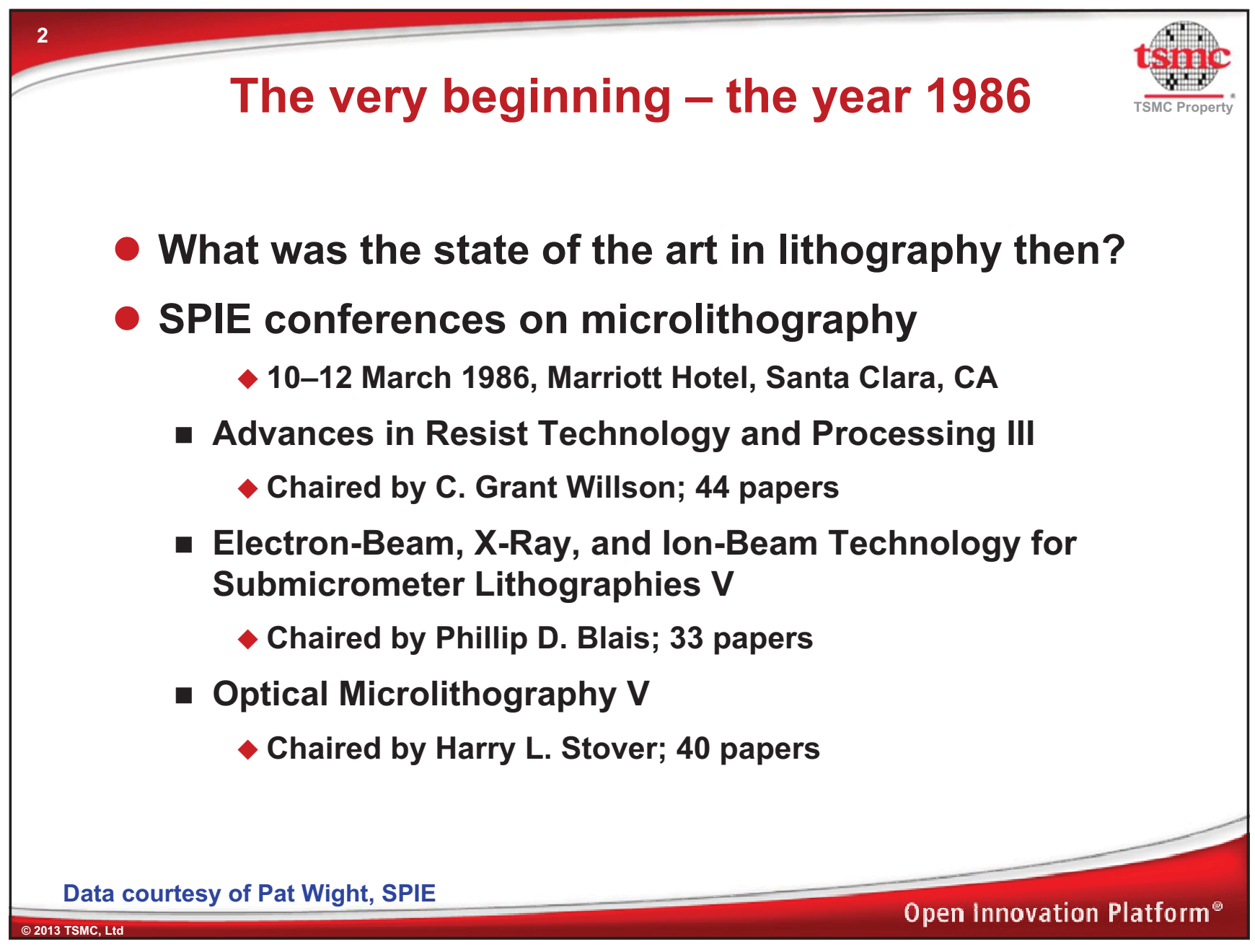




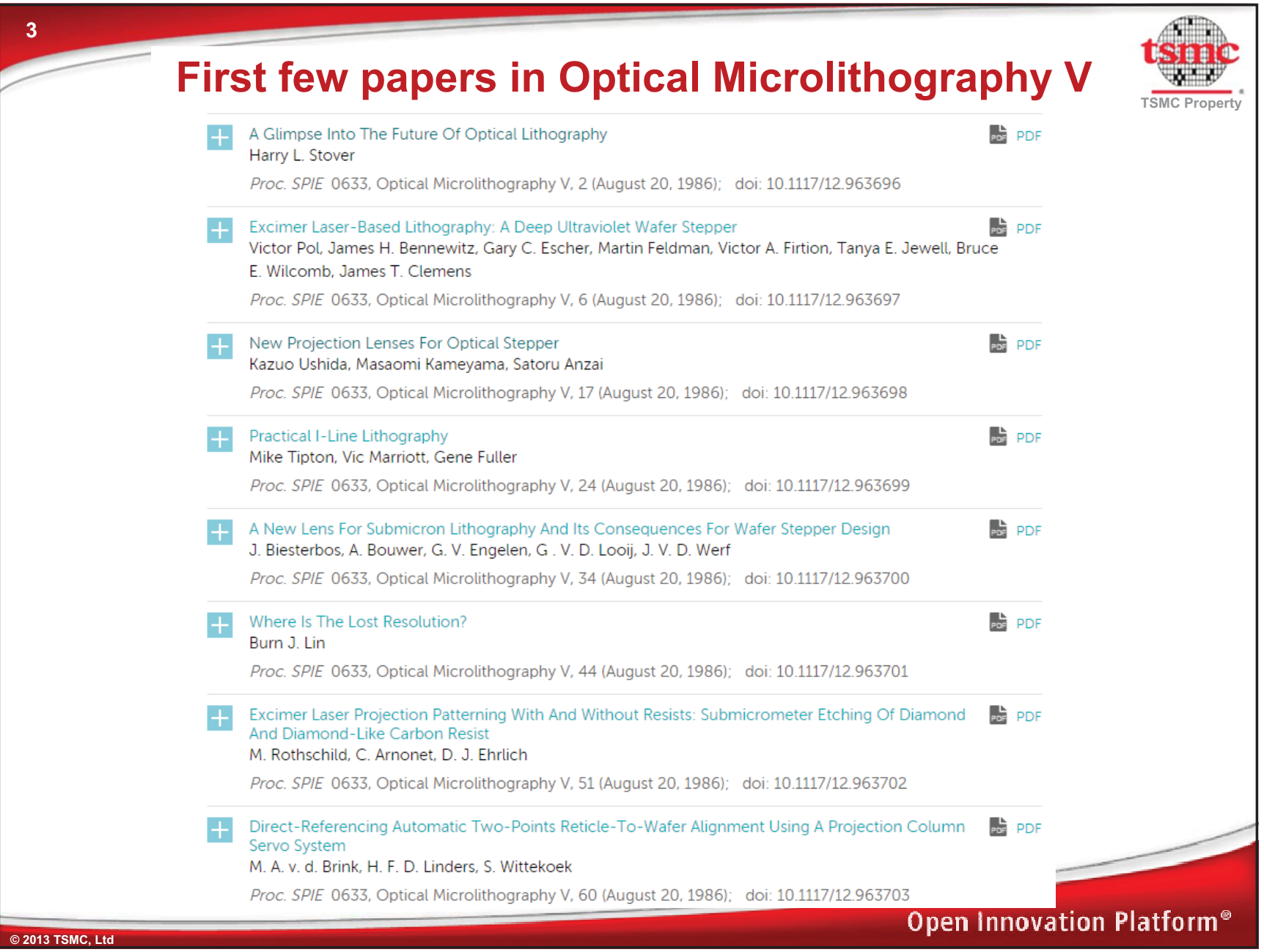

Proc. of SPIE Vol. $9776977632-3$ 


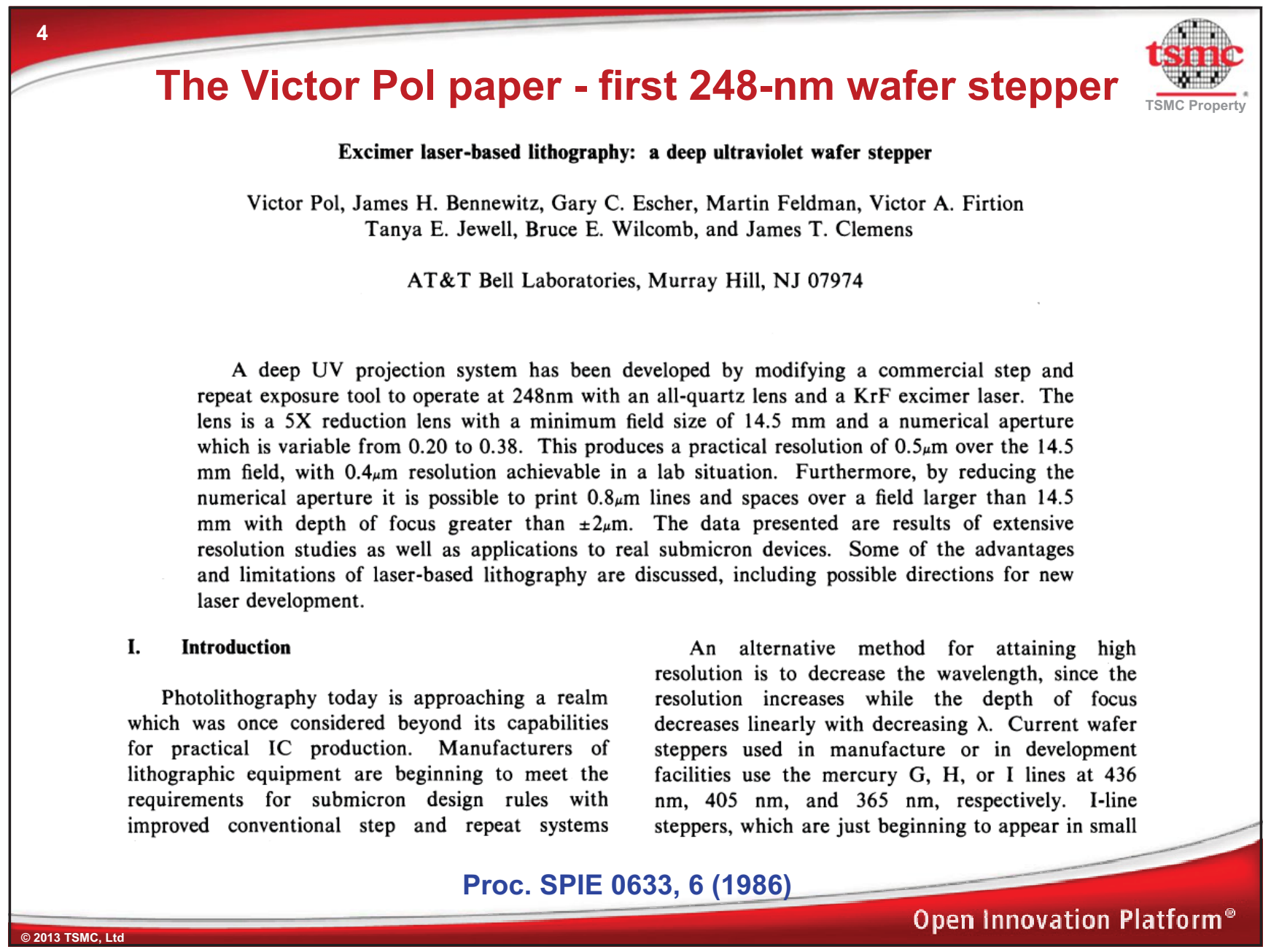




\title{
5 \\ And what did the conference chair have to say?
}

\section{CHAIRMAN'S OVFRVIEW}

"A Glimpse into the Future of optical Lithography"

\author{
Harry L. Stover \\ ASM Lithography \\ Veldhoven, The Netherlands
}

\section{ABSTRACT}

The conference papers relating to resolution and overlay of exploratory but production-worthy exposure/alignment systems indicate performance far exceeding current IC manufacturing demands, and hence give a glimpse of future production systems and design rules. A summary table is presented.

\section{and the paper's final paragraphs:}

Meaning: What do all these impressive developments mean to users and to the competitive lithographic technologies? Well, there is good news and there is bad news! The good news, to chip manufacturers, is that they can sleep easier tonight, knowing that they can count on optical microlithography to continue the gradual but stable evolution that has given ever-increasing productivity, - unprecendented in history, to the microelectronic industry. (They can now devote their waking enerqies to creating new chip demand, to pull the industry out of this recession).

The bad news, to the competing replication technologies such as $\mathrm{x}$-ray and flood ion-beam systems, is that they can still expect a very long bridesmaid wait by the telephone before they will be called upon to fill a void in high-volume IC manufacturing left by optical microlithography.

I thank all of you for your extraordinary response, in quantity and quality of papers, and in your attendance to the Fifth Annual SPIE Conference on optical Microlithography.

Proc. SPIE 0633, 3 (1986) 


\section{6 \\ The first announcement on EUV lithography}

Extended Abstracts (The $47^{\text {th }}$ Autumn Meeting,1986) ;

The Japan Society of Applied Physics

\section{8-ZF-15 Study on X-ray Reduction Projection Lithography}

NTT ETL Hiroo Kinoshita, Ryuji Kaneko, et al.
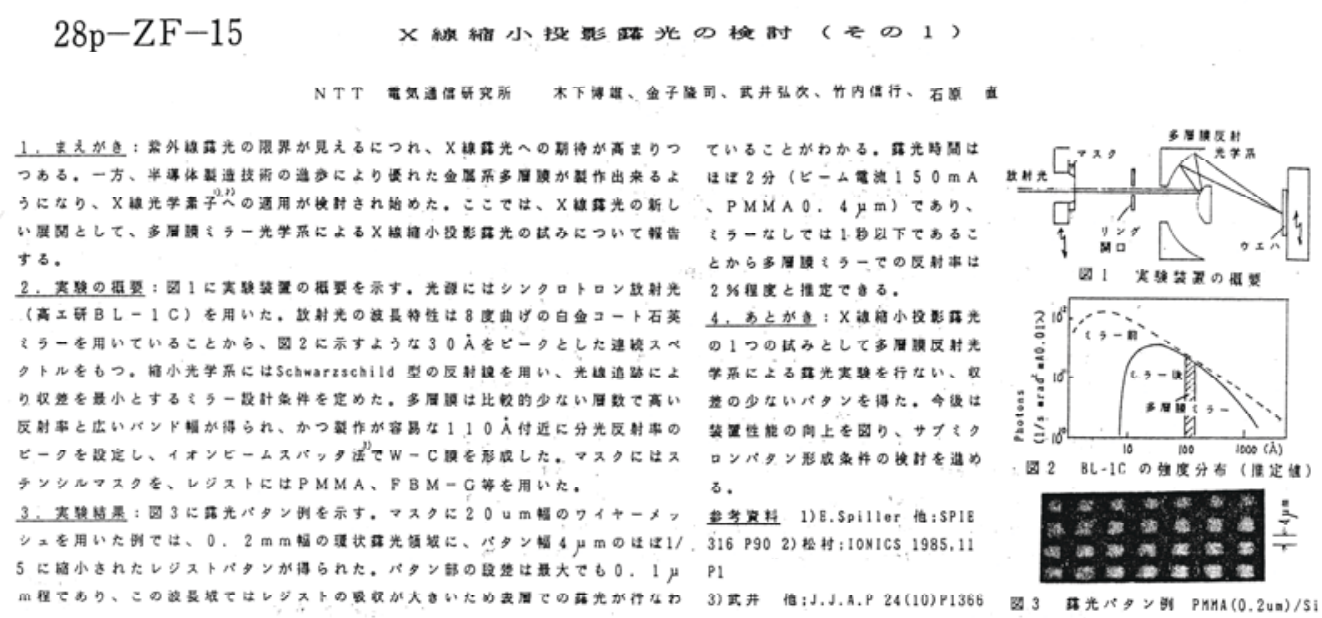

Hiroo Kinoshita, "30 years have passed from the first experiment,"

International Symposium on EUVL, Maastricht, the Netherlands, 6 Oct. 2015 


\section{7 \\ Details of Kinoshita's setup and results

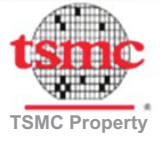

Si Stencil Mask W/C Multilayer Coating Optics

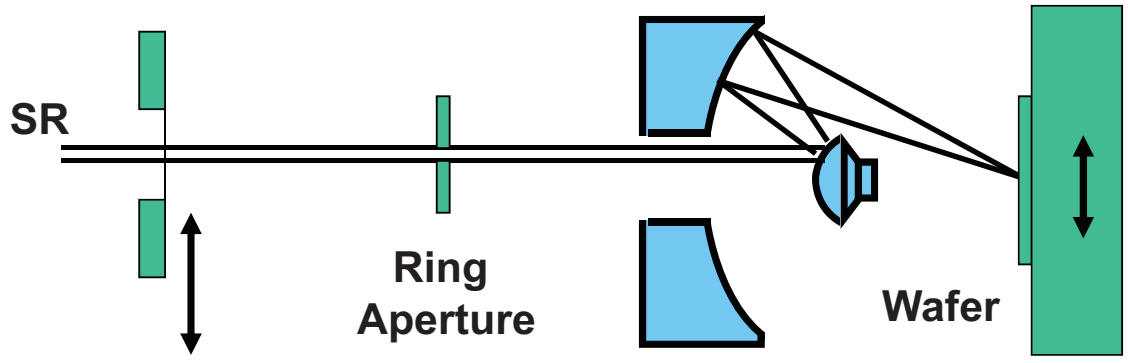

$\lambda=11 \mathrm{~nm}$, provided by synchrotron radiation

\section{$8 X$, ring-field}

Schwarzschild optics; exposure carried out by scanning mask and wafer

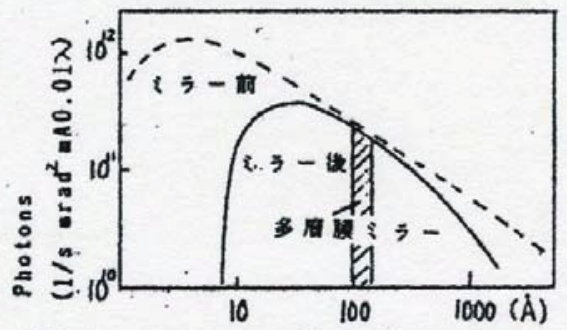

\begin{tabular}{|c|c|c|c|c|c|c|}
\hline $7 x$ & $3 x$ & 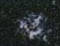 & 120 & $8 \%$ & 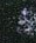 & $\%$ \\
\hline 4 & 4 & 8 & 85 & 4 & 8 & 4 \\
\hline & 4 & 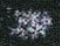 & 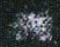 & 2 & & 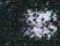 \\
\hline & 10 & 34 & 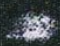 & 25 & 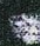 & 称 \\
\hline
\end{tabular}

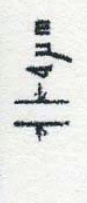

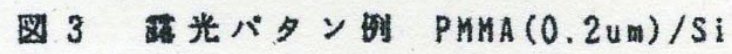

国 2 BL-1C，の强度分布（僬定侹）

Hiroo Kinoshita, "30 years have passed from the first experiment,"

International Symposium on EUVL, Maastricht, the Netherlands, 6 Oct. 2015 


\section{8 \\ What motivated him to work on EUVL?}

I was involved in research on X-ray proximity lithography (XPL) around 1983.

At that time, the target resolution for XPL was $0.5 \mu \mathrm{m}$, which was thought to be difficult to achieve with ultraviolet lithography.

We had already developed apparatus for S\&R type XPL and examined its applicability to the trial production of devices...

Our assessment was that the exposure machine and resist performance seemed quite adequate; but we ran into too many problems with the manufacture of proximity masks.

It was around that time that I began to seriously consider $\mathrm{X}$ ray reduction lithography as a more viable alternative (to $X P L)$. 


\section{9}

\section{And what were the reactions to his announcement? $\frac{\sin }{\text { smacroperty }}$}

The response to the announcement was rather negative. People seemed unwilling to believe that we had actually made an image by bending X-rays, and they tended to regard the whole thing as a big fish story.

However, my belief remained unshaken that "theoretically, it is possible to produce an image using a reduction optical system consisting of a couple of mirrors coated with multilayer film." 


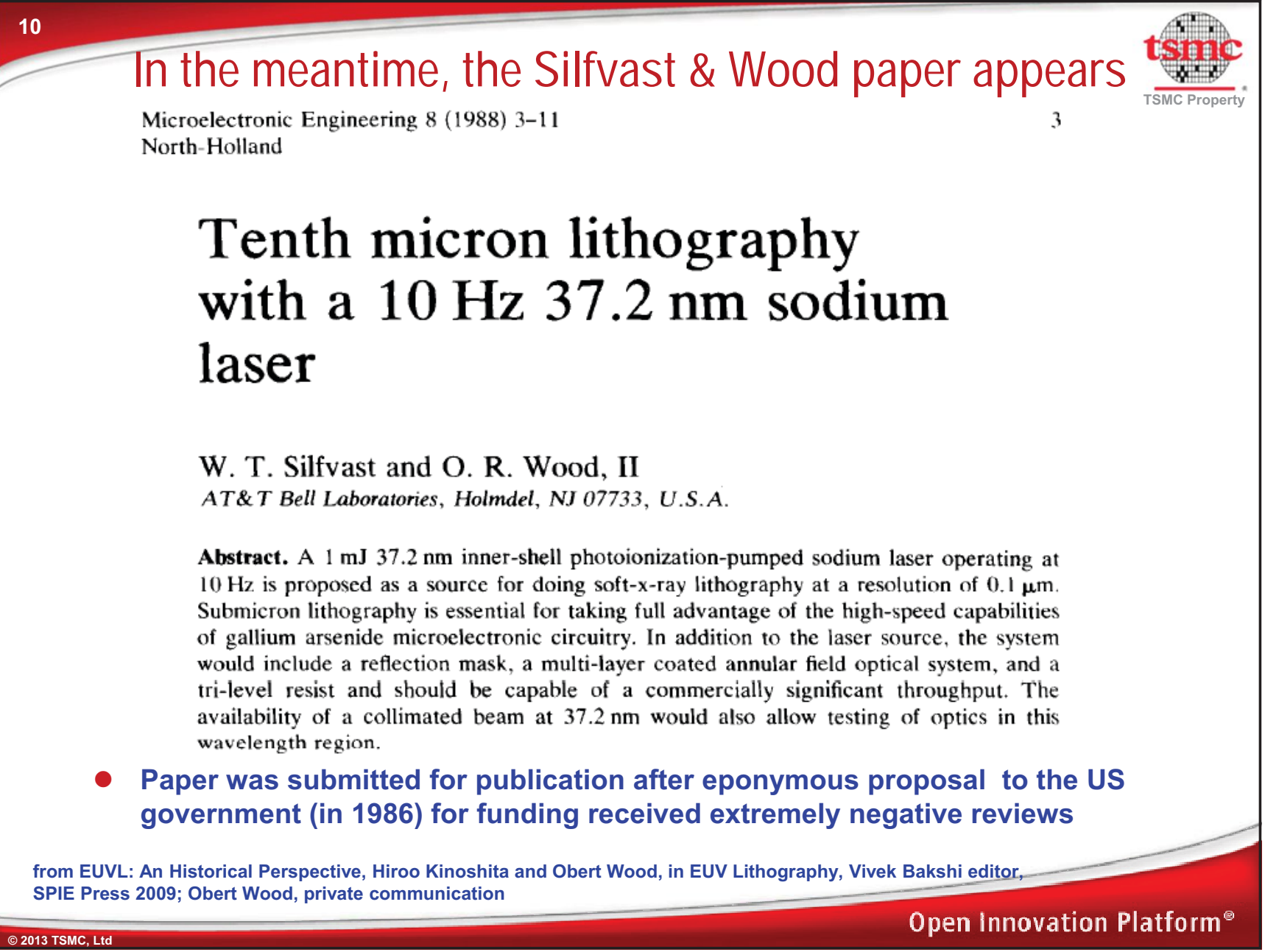




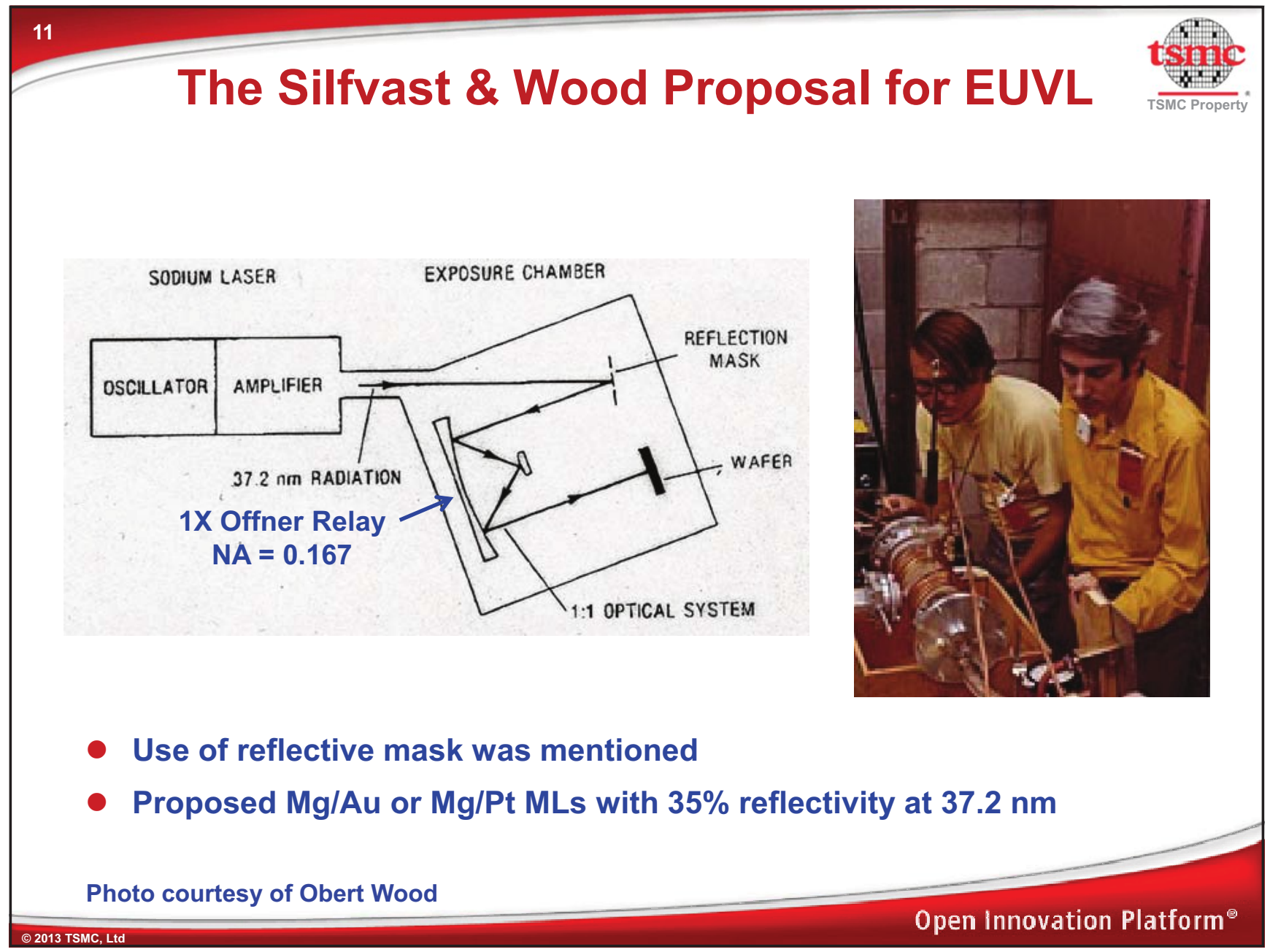

Proc. of SPIE Vol. 9776 977632-11 


\section{2 \\ Bell Lab's experimental results, two years later}

- Nevertheless, under the leadership of Rick Freeman and Bill Brinkman, a Bell Lab team was assembled to work on EUVL in 1988

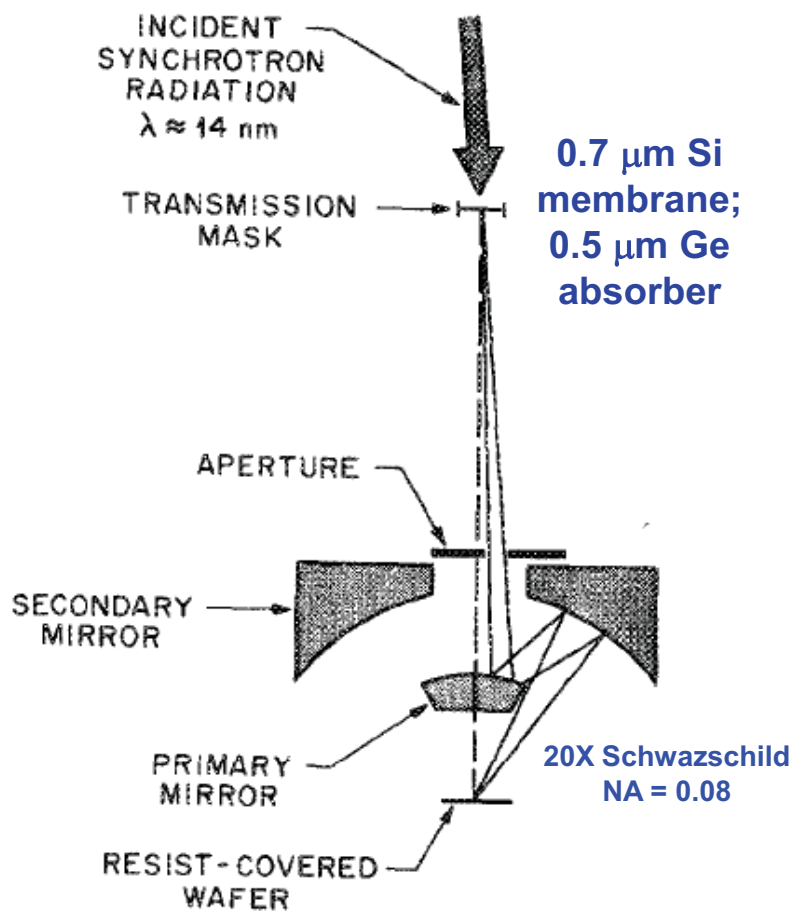

Reproduced from J. E. Bjorkholm et al., JVST B 8, 1509, Nov/ Dec 1990, with the permission of American Vacuum Society.

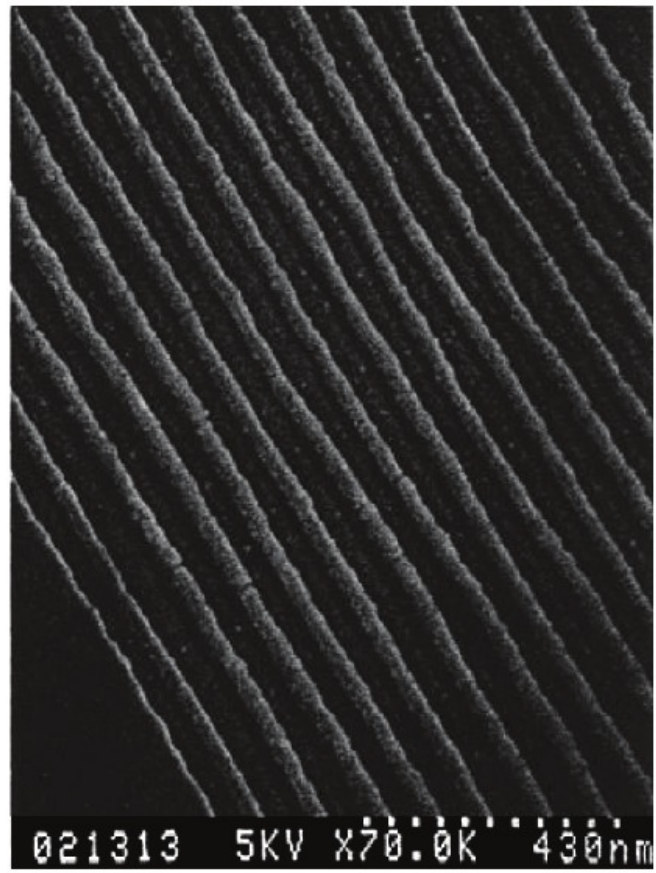

Pitch $=100 \mathrm{~nm}$

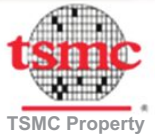




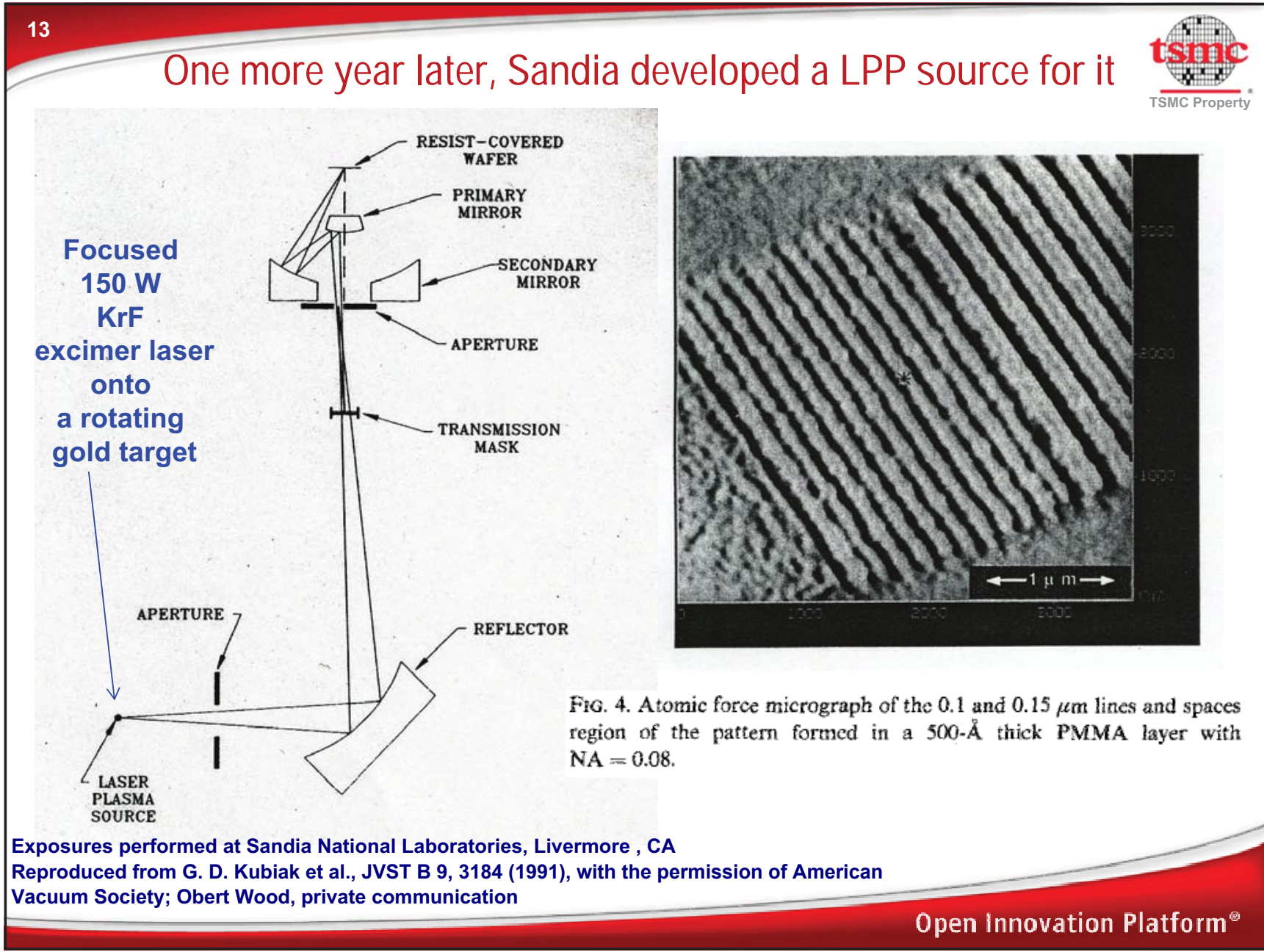




\title{
14 \\ Independently, at 1988 3-beams conference in Ft. Lauderdale

\section{Soft $x$-ray projection lithography using an x-ray reduction camera}

\author{
Andrew M. Hawryluk and Lynn G. Seppala \\ Lawrence Livermore National Laboratory, University of California, Livermore, California 94550
}

(Received 2 June 1988; accepted 15 August 1988)

\begin{abstract}
Soft $\mathrm{x}$-ray projection lithography can now be realized with recent developments in $\mathrm{x}$-ray optics. Using new $x$-ray optical components and spherical imaging optics, we have designed an $x$-ray reduction camera which is capable of projecting with soft $x$-ray radiation, a $5 \times$ demagnified image of a mask onto a resist coated wafer. The resolution of this design is $\sim 100 \mathrm{~nm}$ with a depth of focus of $\pm 5.6 \mu \mathrm{m}$ and a 0.5 -cm-diam image field. We use $x$-ray reflecting masks (patterned $x$ ray multilayer mirrors) which are fabricated on thick substrates and can be made relatively distortion free. Our design uses a laser produced plasma for the x-ray source. Better resolution and/or larger areas are possible with improvements in optic figures and source characteristics.
\end{abstract}

\section{INTRODUCTION}

New advances in the field of $x$-ray optics have been responsible for many new $\mathrm{x}$-ray optical components such as normal incidence soft $x$-ray mirrors, beamsplitters, and highly dispersive multilayer mirrors. ${ }^{1,2}$ These new optical components have made it possible to design and build new instruments such as $\mathrm{x}$-ray microscopes, telescopes, waveguides, and interferometers. Another application is a new form of lithography which projects an image using soft $\mathrm{x}$-ray radiation. ondary photoelectrons generated in the photoresist (which could degrade the resolution) is small ( $\sim 5 \mathrm{~nm})$. At $4.5 \mathrm{~nm}$, the $x$-ray absorption depth in resist is large $(>1 \mu \mathrm{m})$, and the depth of focus of our inverse Cassegrainian system is $\pm 5.6 \mu \mathrm{m}$. This large depth of focus at the image plane along with the large $x$-ray absorption depth in resists at $4.5 \mathrm{~nm}$ would allow us to expose thick $(\sim 1 \mu \mathrm{m})$ resists. However, it should be noted that other soft-x-ray wavelengths $(\lambda=2$ $25 \mathrm{~nm}$ ) can be used. 


\section{Both LPP source and ML masks were proposed in the Hawryluk \& Seppala paper}

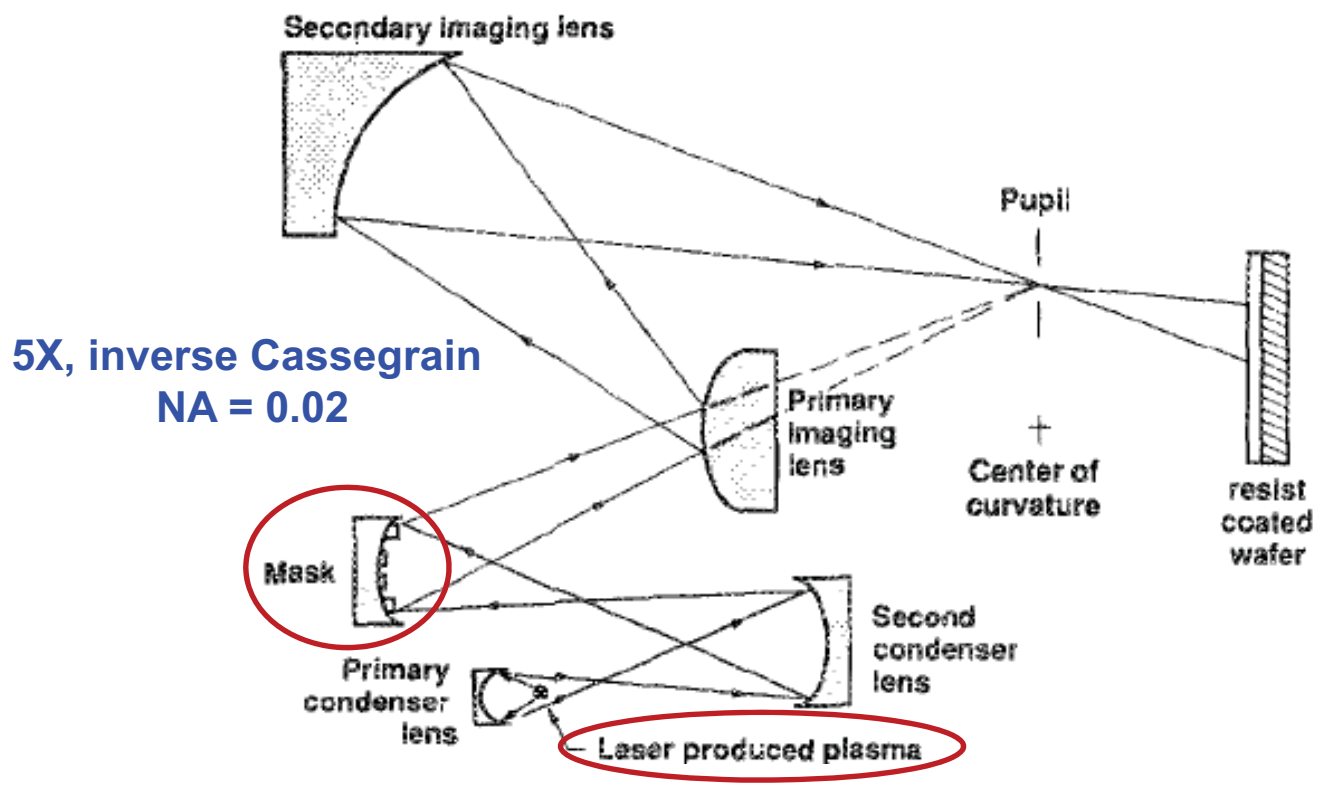

Reproduced from Hawryluk et al., JVST B 6, 2162, Nov/Dec 1988, with the permission of American Vacuum Society. 


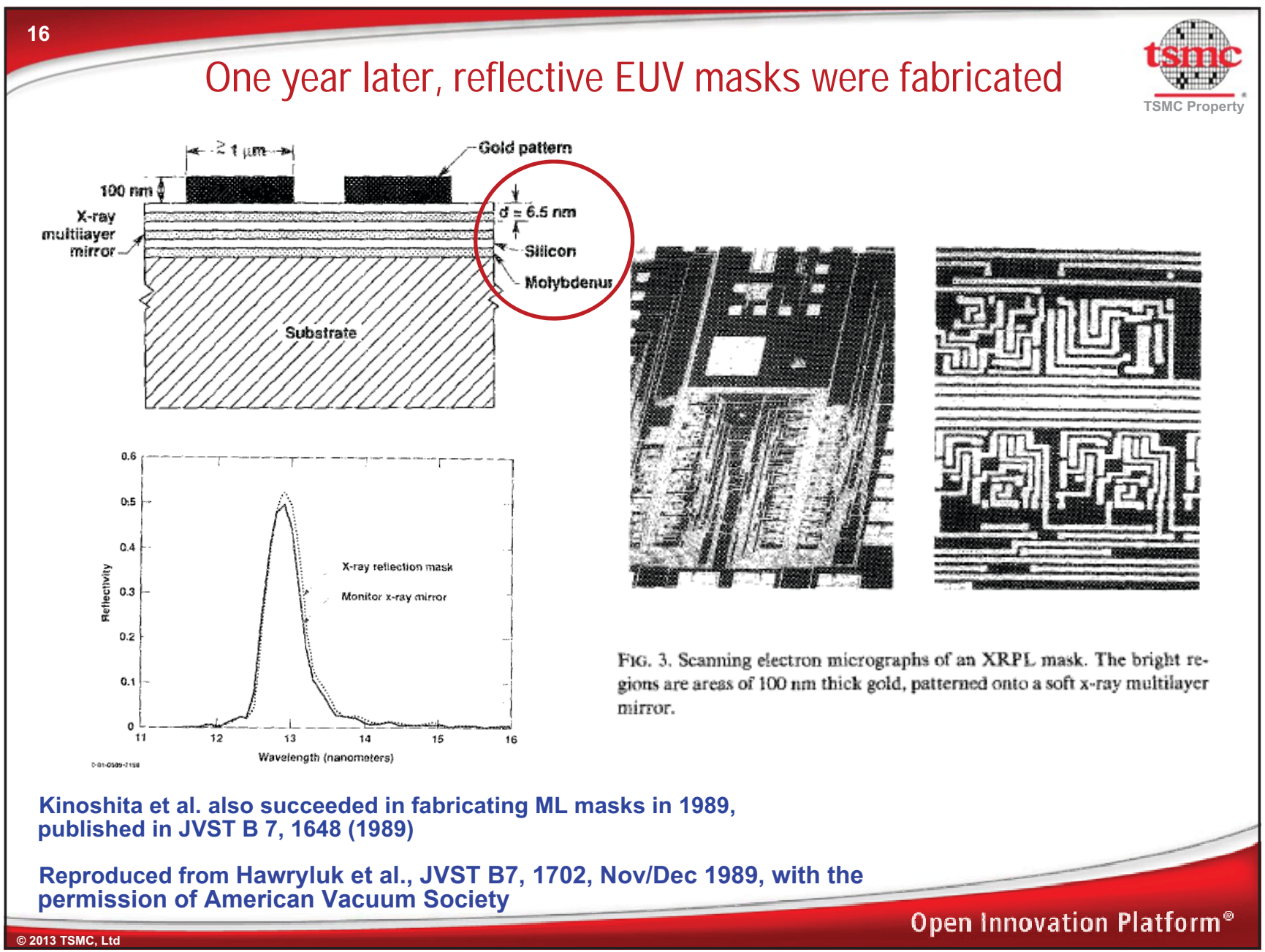




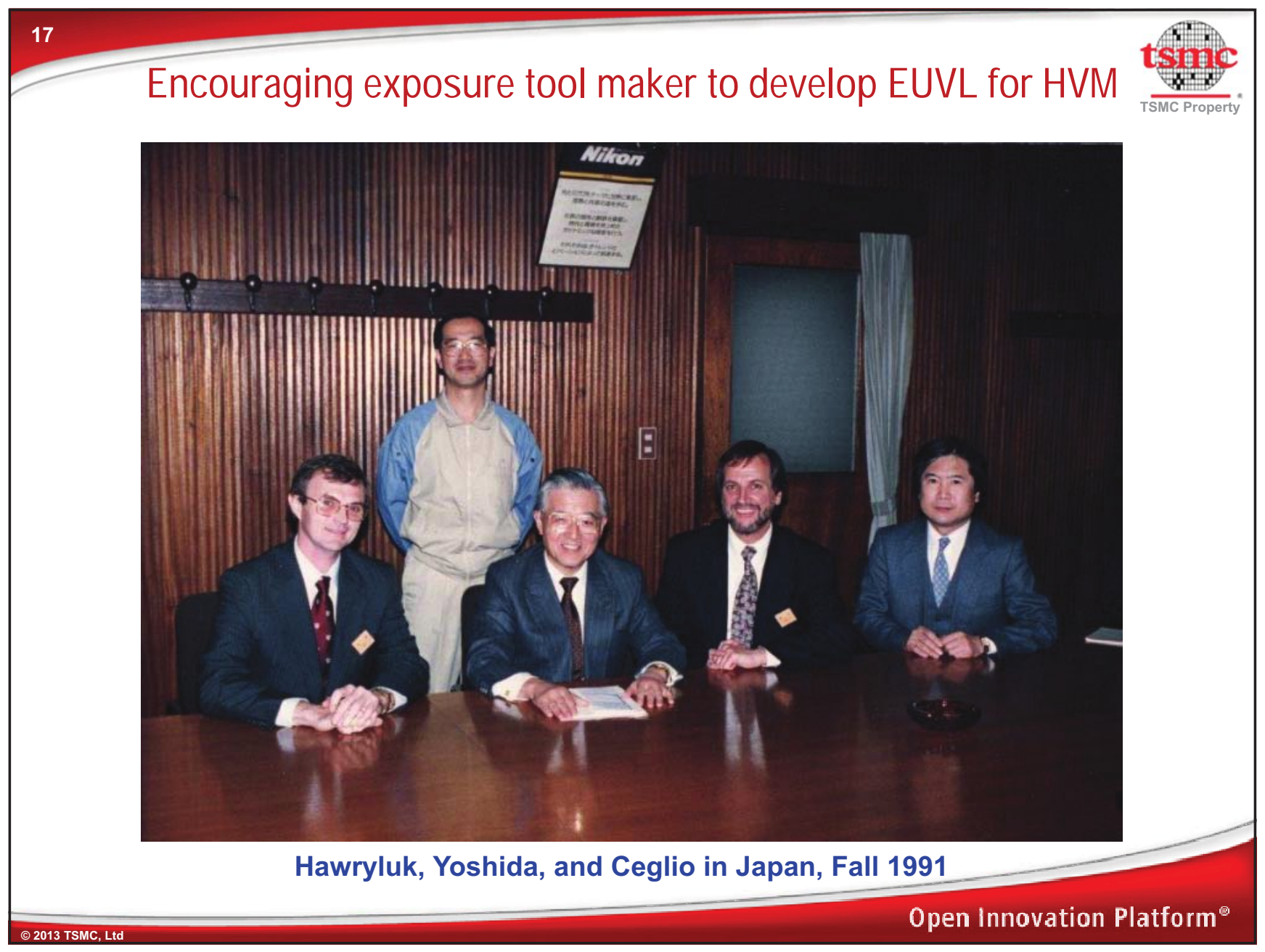

Proc. of SPIE Vol. $9776977632-17$ 


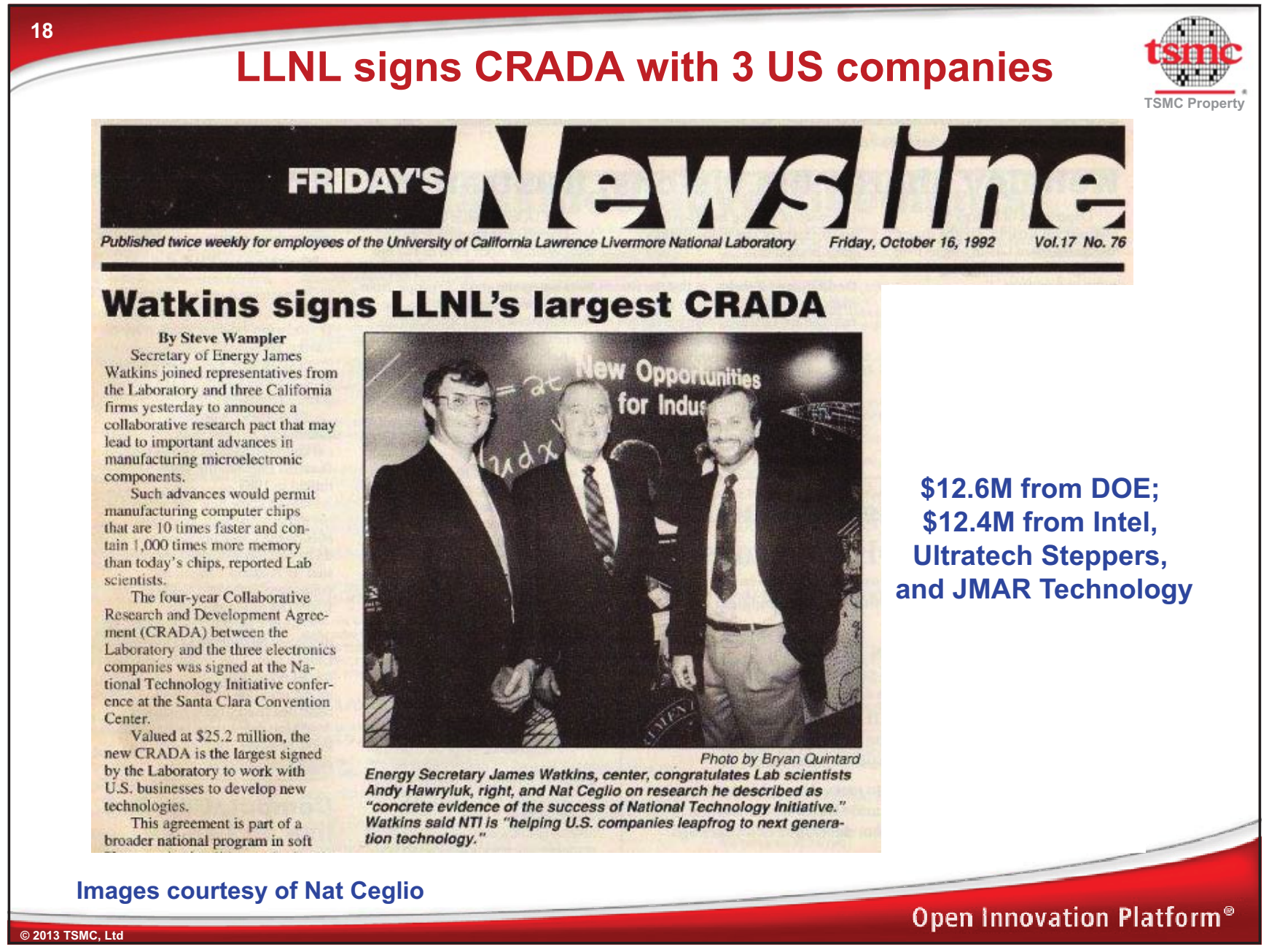




\section{Groups came up with the EUVL idea independently $\frac{\$ \rightarrow \infty}{\text { Tsmoropory }}$}

NTT

- Kinoshita wanted improve the performance of proximity $x$-ray lithography, by adding optics between the mask and the wafer

- Bell Labs

- Silfvast and Wood proposed using a new soft x-ray laser to illuminate a lithographic system to achieve better resolution in projection lithography

- LLNL

- Hawryluk et al. wanted to apply the lab's expertise on the fabrication of normal-incidence soft $x$-ray optics to the realization of a new lithographic system

Hiroo Kinoshita, "30 years have passed from the first experiment,"

International Symposium on EUVL, Maastricht, the Netherlands, 6 Oct. 2015;

Obert Wood, private communication

Andy Hawryluk and Nat Ceglio, private communication 


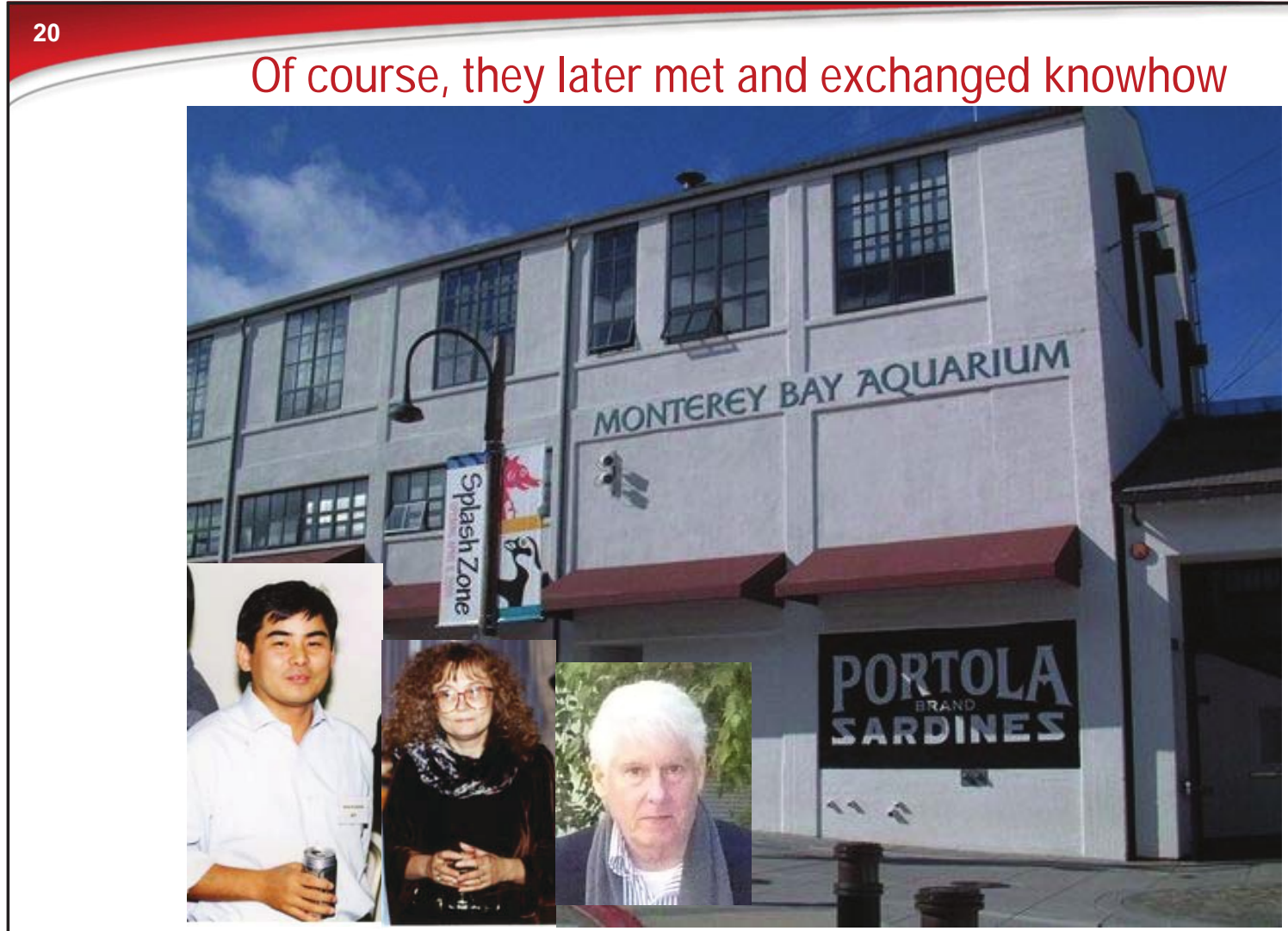

"At the banquet of 19893 Beams conference, Tanya Jewell and Obert Wood asked me about my (telecentric, with aspherical mirrors) reduction camera. But I could not hear her Russian accented English. So Obert translated her English. Obert also translated my Japanese English. Discussion continued until the end of the banquet. I could not eat anything." - Hiroo Hinoshita 


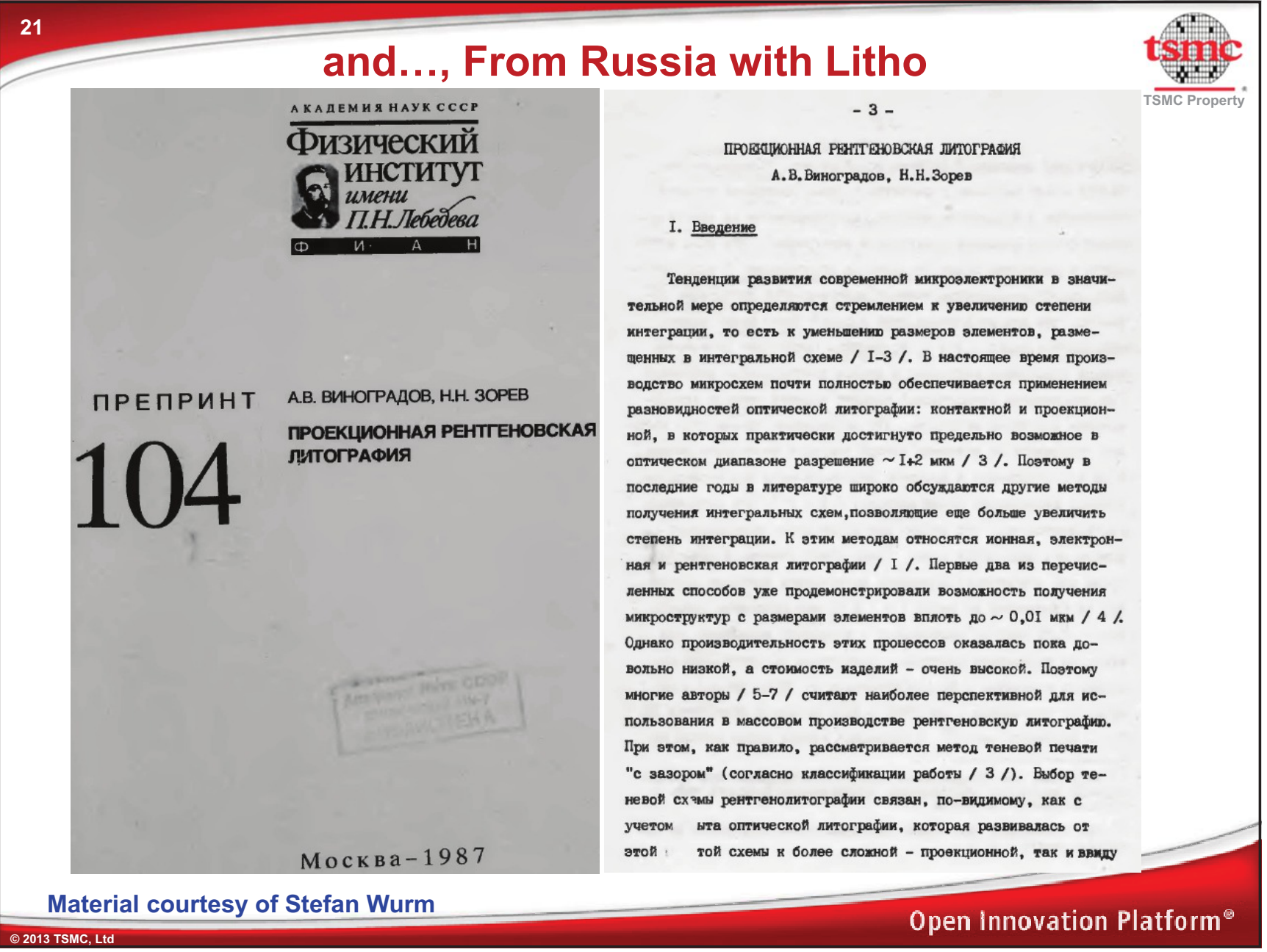




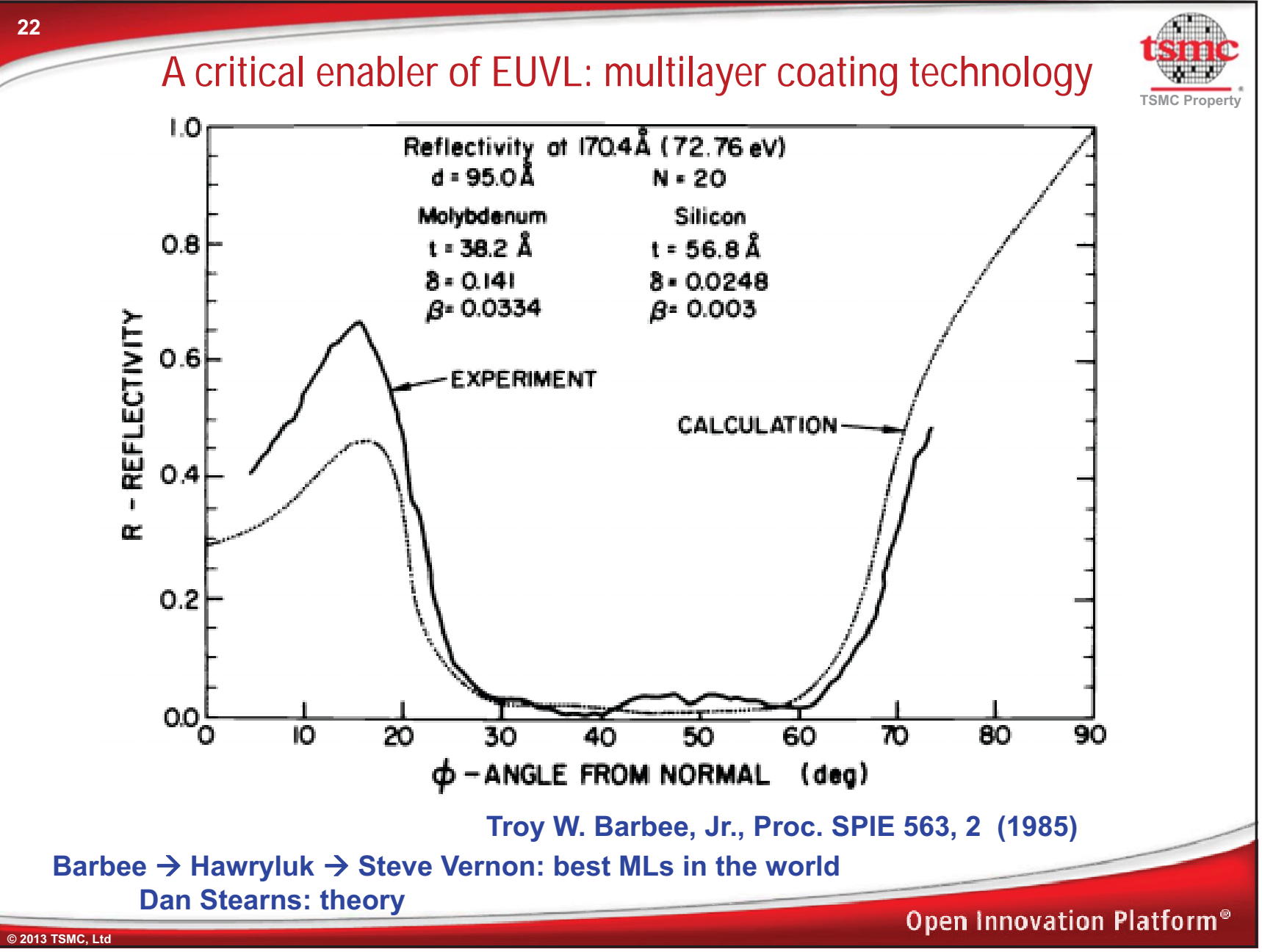




\section{How did we end up with the name EUV?}

"Soft x-ray projection lithography" was what we originally named it until DARPA asked us to get " $x$-ray" out of the name in 1993. So it was renamed "Extreme Ultraviolet Lithography" - I suggested that name because I knew Berkeley had an "Extreme Ultraviolet Astronomy" group. At the time nobody in our group even knew what the wavelengths of EUV were - but we needed a new name...quick.

Nat Ceglio, private communication 


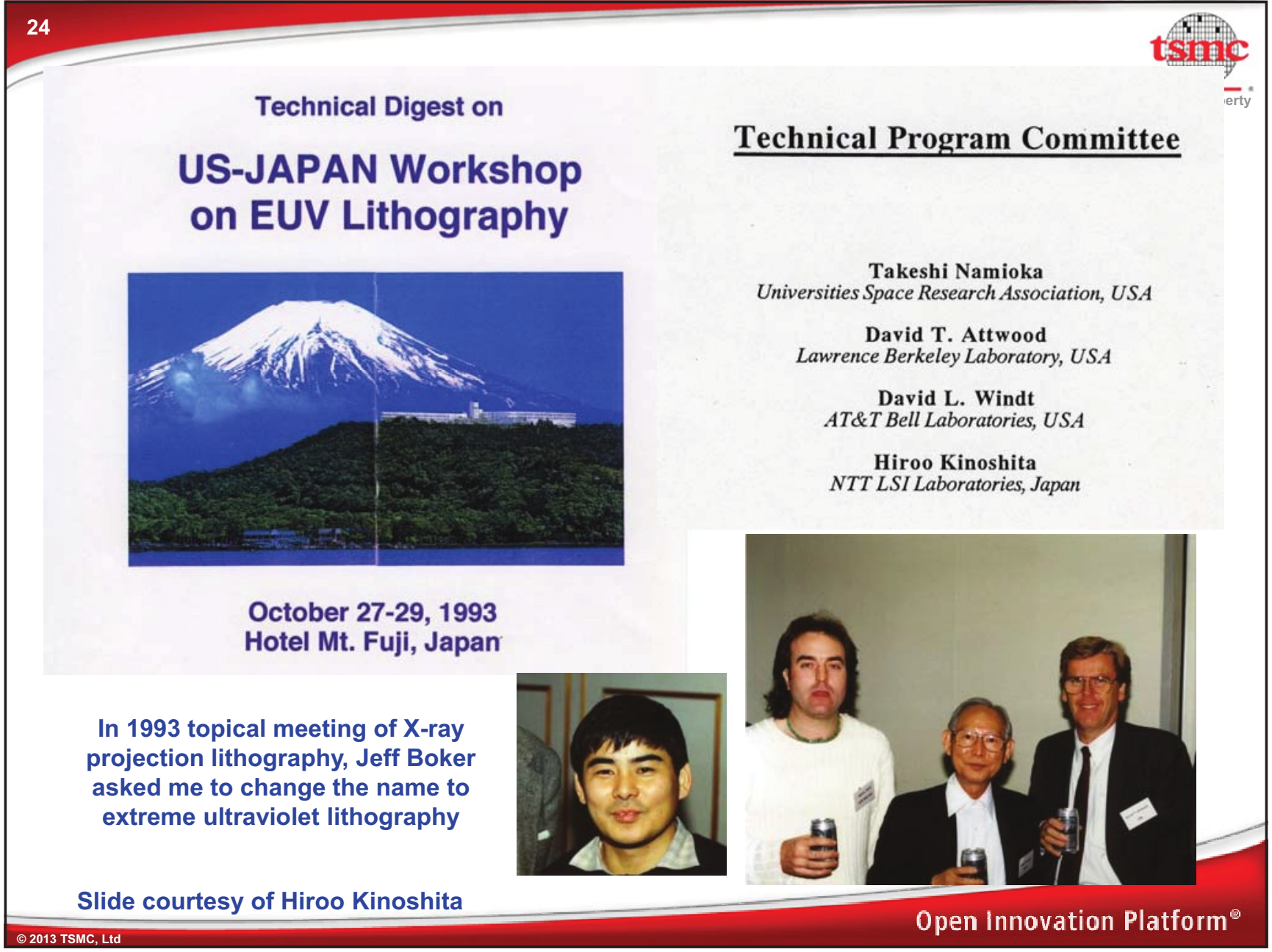


- HIT, in collaboration with Hitachi and Nikon started to develop a threeaspheric mirror system called the ETS-1 in 1996. System was built in 1998

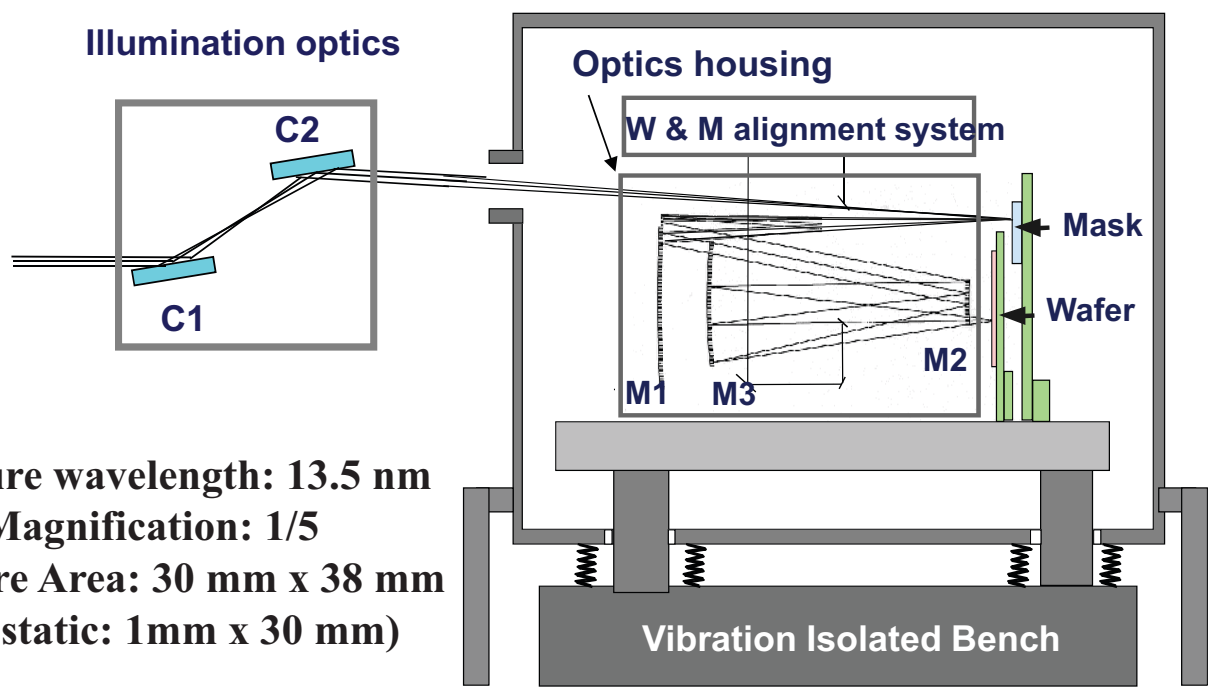

Exposure wavelength: $13.5 \mathrm{~nm}$

Magnification: 1/5

Exposure Area: $30 \mathrm{~mm} \times 38 \mathrm{~mm}$

( static: $1 \mathrm{~mm} \times 30 \mathrm{~mm}$ ) 


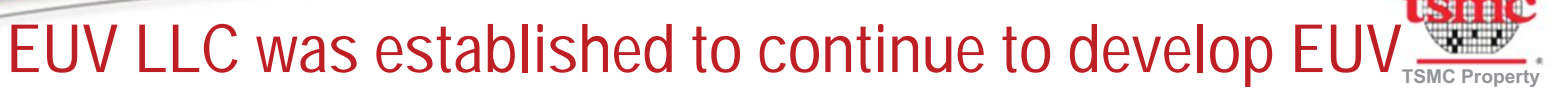

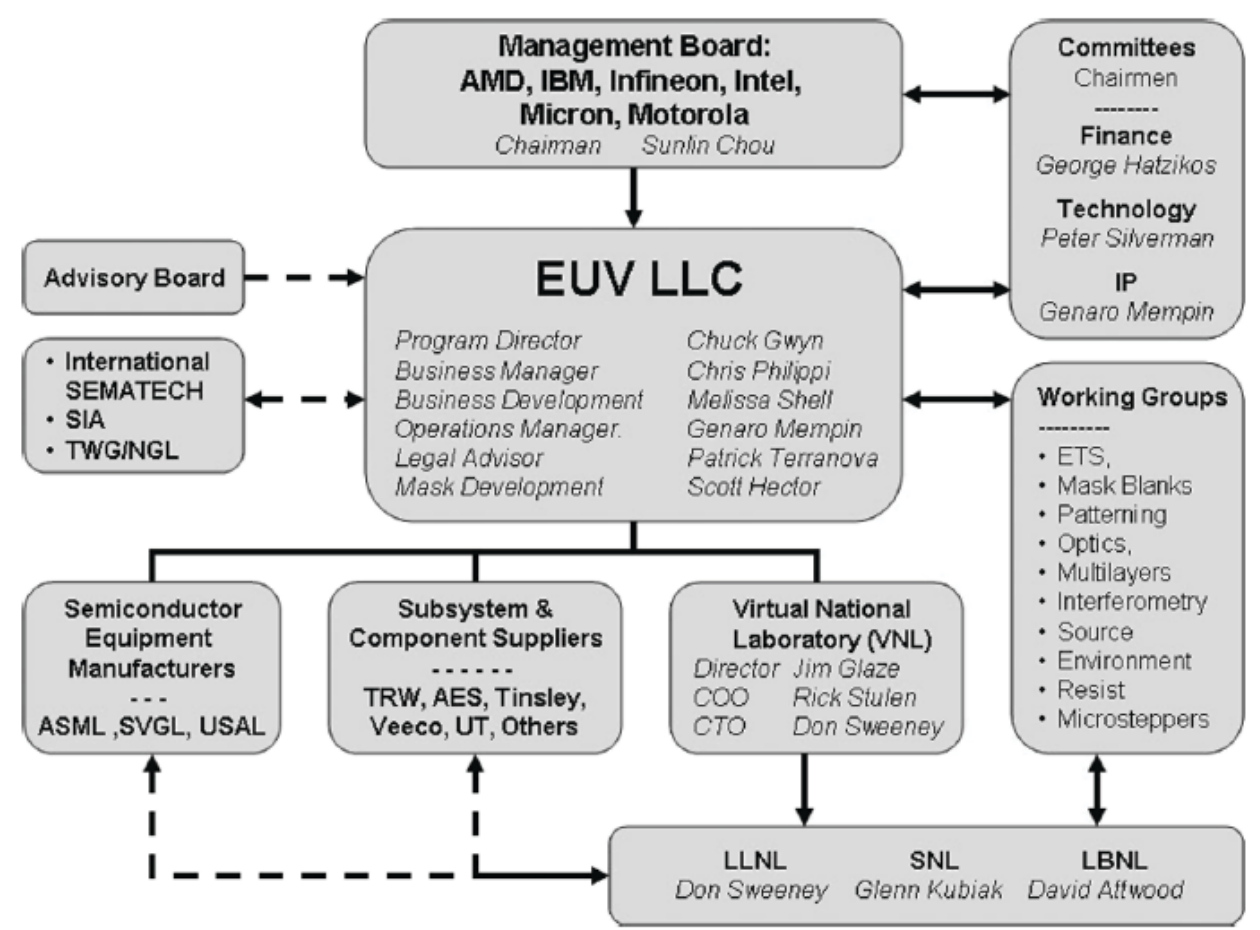

from EUV LLC: An Historical Perspective, by Chuck Gwyn and Stefan Wurm in EUV Lithography, edited by Vivek Bakshi, SPIE Press 2009 
Virtual National Laboratory established to carry out R\&D
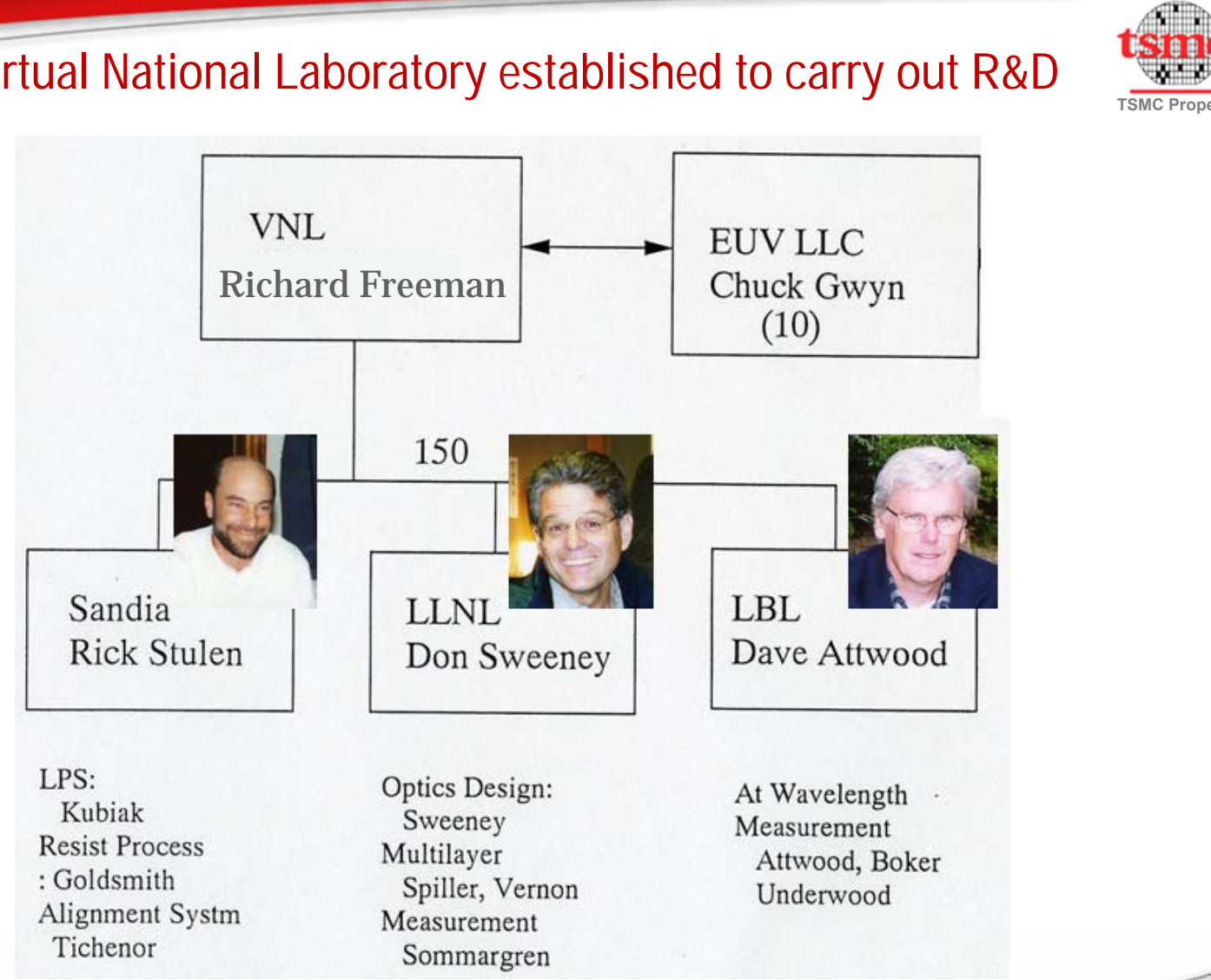


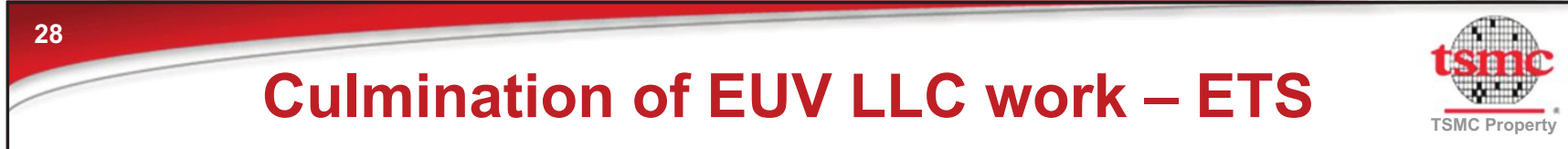

\subsection{NA, 4 mirrors, $24 \times 32.5 \mathrm{~mm}$ imaging field}

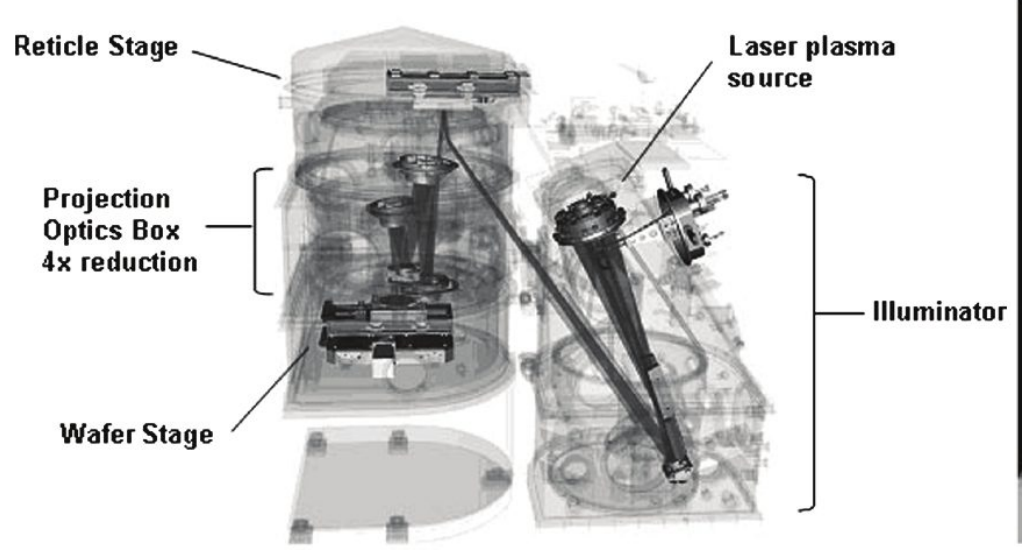

Schematic drawing

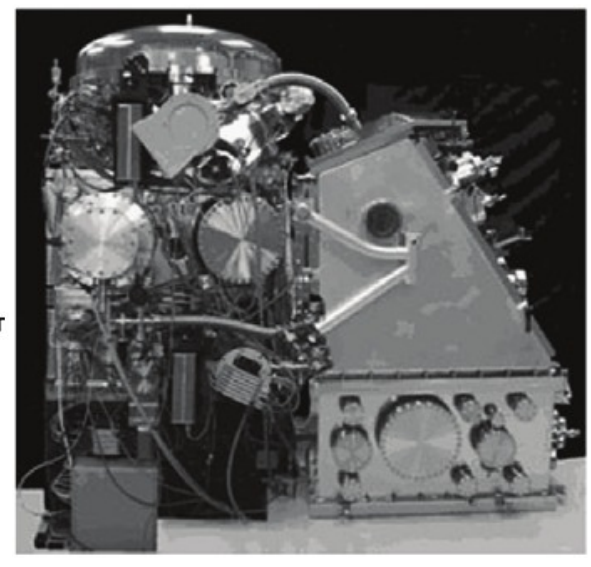

Initial assembly

from EUV LLC: An Historical Perspective, by Chuck Gwyn and Stefan Wurm in EUV Lithography, edited by Vivek Bakshi, SPIE Press 2009 


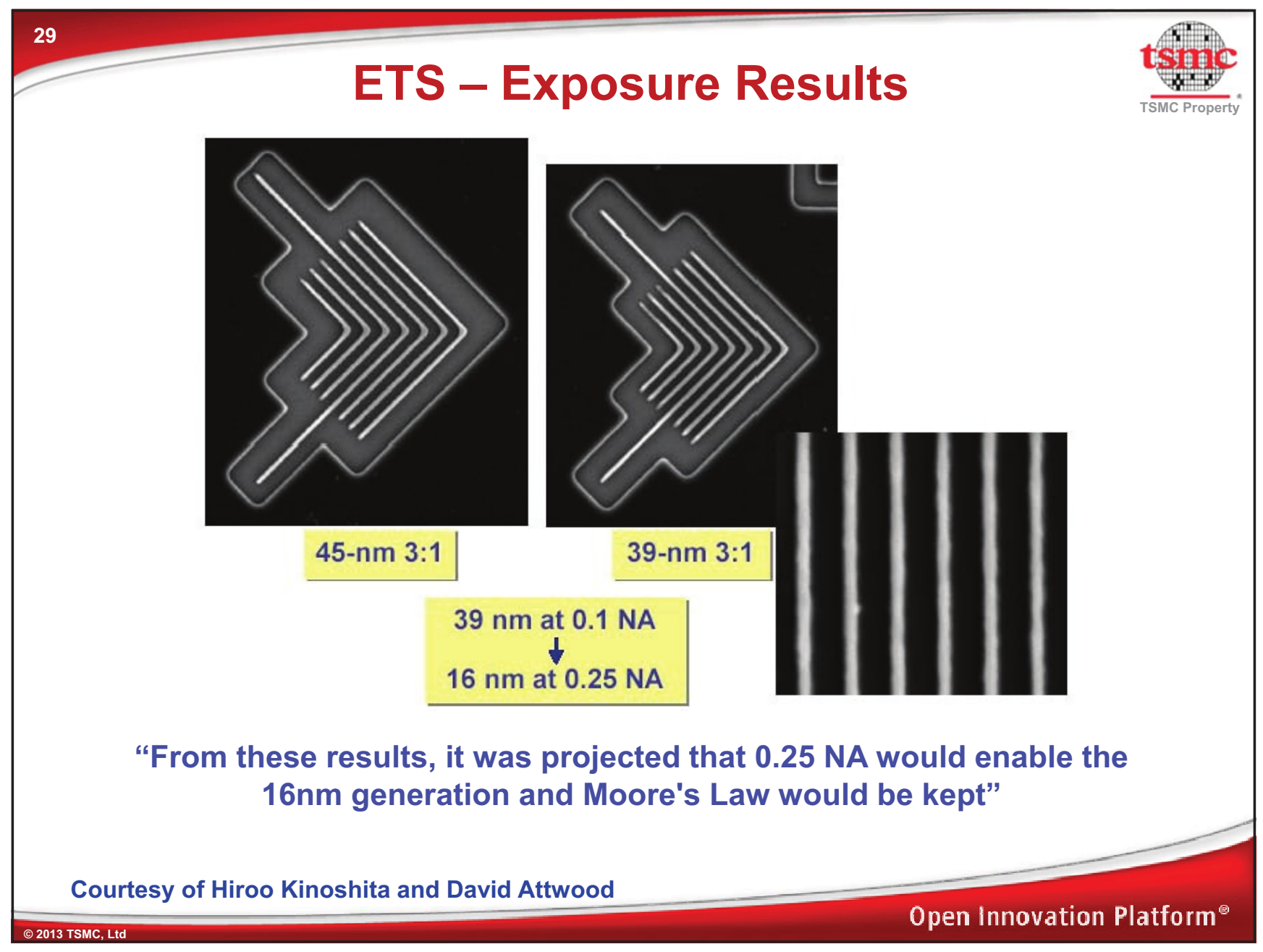

Proc. of SPIE Vol. $9776977632-29$ 


\section{0 \\ Overview of EUV funding Projects in Europa}

\begin{tabular}{|c|c|c|c|c|c|c|c|c|c|c|c|c|c|c|c|c|c|c|c|}
\hline Project & Program & 97 & 9899 & 0 & 12 & 2 & $3 \mid 4$ & 5 & 6 & 7 & 89 & 10 & 1112 & 213 & $14 \mid 1$ & 1516 & 1718 & $39 \mid 2$ & Project Goals \\
\hline EUCLIDES & ESPRIT & & & & & & & & & & & & & & & & & & EUV Optics Basics \\
\hline PREUVE & National (F) & & & & & & & & & & & & & & & & & & EUV Small field tool \\
\hline EXTATIC & MEDEA+ & & & & & & & & & & & & & & & & & & 45nm EUV $\alpha$-Scanner \\
\hline EXTUMASK & MEDEA+ & & & & & & & & & & & & & & & & & & 45nm EUV Mask \\
\hline EUVSOURCE & MEDEA+ & & & & & & & & & & & & & & & & & & EUV Xe Source \\
\hline EXCITE & MEDEA+ & & & & & & & & & & & & & & & & & & 45nm Process \& Resist \\
\hline MoreMoore & MEDEA+ & & & & & & & & & & & & & & & & & & 32nm Capability \\
\hline EAGLE & MEDEA+ & & & & & & & & & & & & & & & & & & $32 \mathrm{~nm}$ Pre-production EUV scanner \\
\hline EXCEPT & CATRENE & & & & & & & & & & & & & & & & & & 22nm EUV scanner \& Infrastructure \\
\hline ETIK & National (D) & & & & & & & & & & & & & & & & & & 14nm EUV Optics \\
\hline E450EDL & ENIAC & & & & & & & & & & & & & & & & & & EUV Tool System Architecture \& Design \\
\hline E450LMDAP & ENIAC & & & & & & & & & & & & & & & & & & N10 EUV Scanner \\
\hline SENATE & ECSEL & & & & & & & & & & & & & & & & & & N7 EUV Scanner \\
\hline TAKE5 & ECSEL & & & & & & & & & & & & & & & & & & N5 EUV Scanner \\
\hline
\end{tabular}




\section{How was the $13.5 \mathrm{~nm}$ wavelength chosen?}

- Because of the good performance of Mo/Si multilayers, which has to work with wavelength $>12.5 \mathrm{~nm}$

- A new class of Be based MLs were developed, ... Mo/Be MLs with measured reflectivity approaching $70 \%$ were demonstrated at 11.3 $\mathrm{nm}$, the highest experimental reflectivity achieved at any EUV wavelength at that time

- In 1999 - 2000 the international semiconductor community abandoned the Be-based MLs and the 11-nm wavelength region for EUVL, mainly due to health and safety issues associated with the toxicity of Be particles. The focus was shifted to ML optimization for the 13.5-nm region 


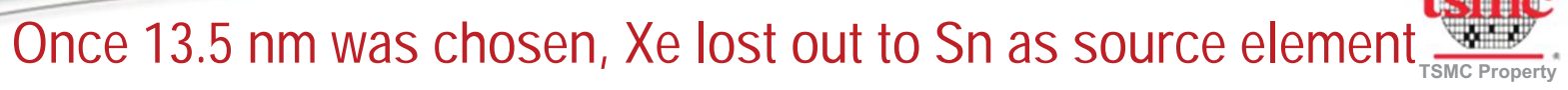

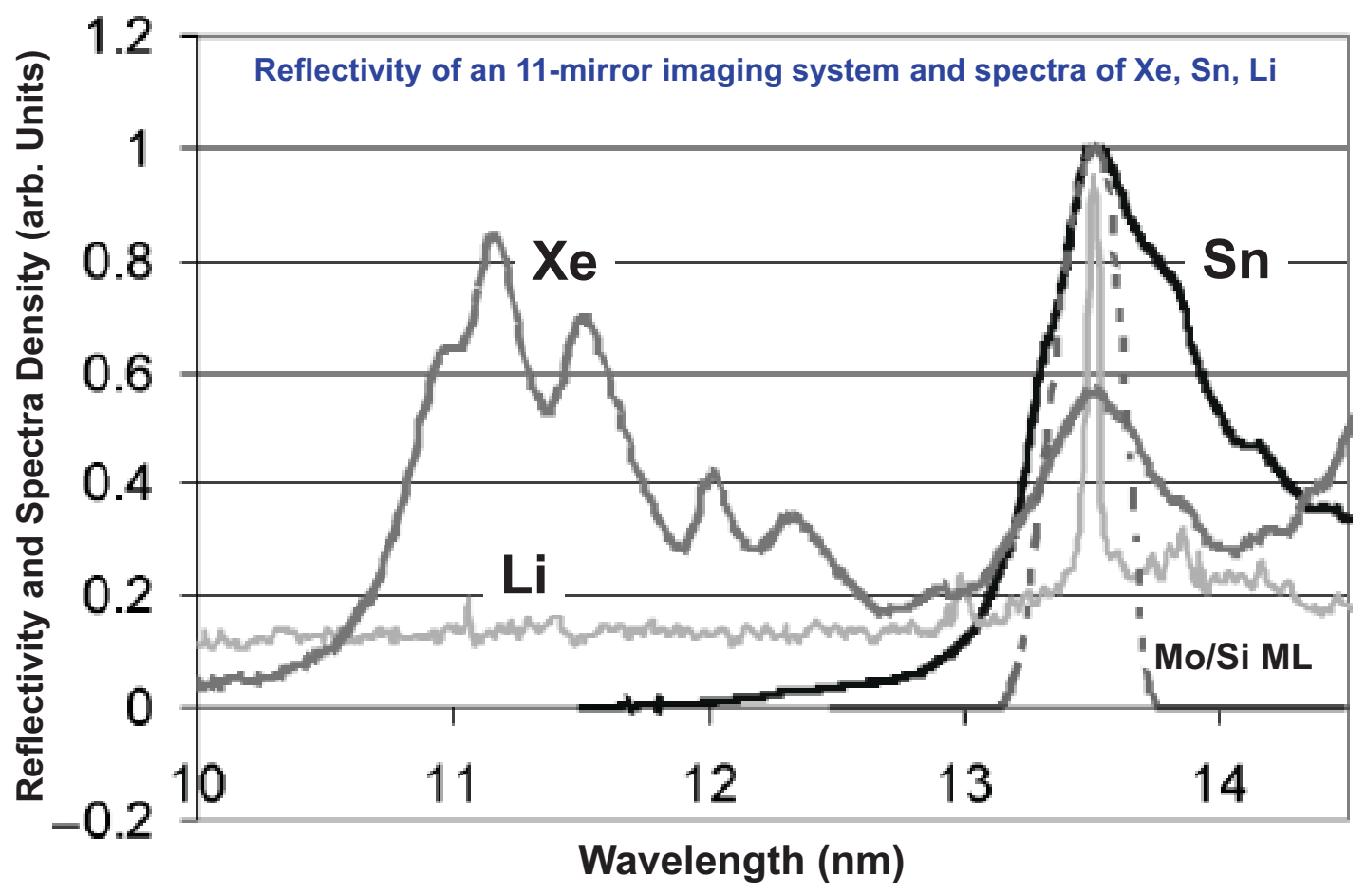

from EUV Source Requirements for EUVL, by K. Ota, Y. Watanabe, V. Banine, H. Franken in EUV Sources for Lithography, edited by Vivek Bakshi, SPIE Press 2006 


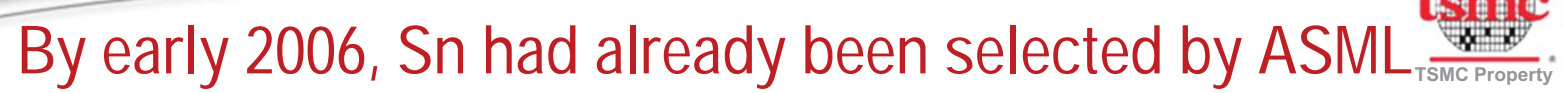

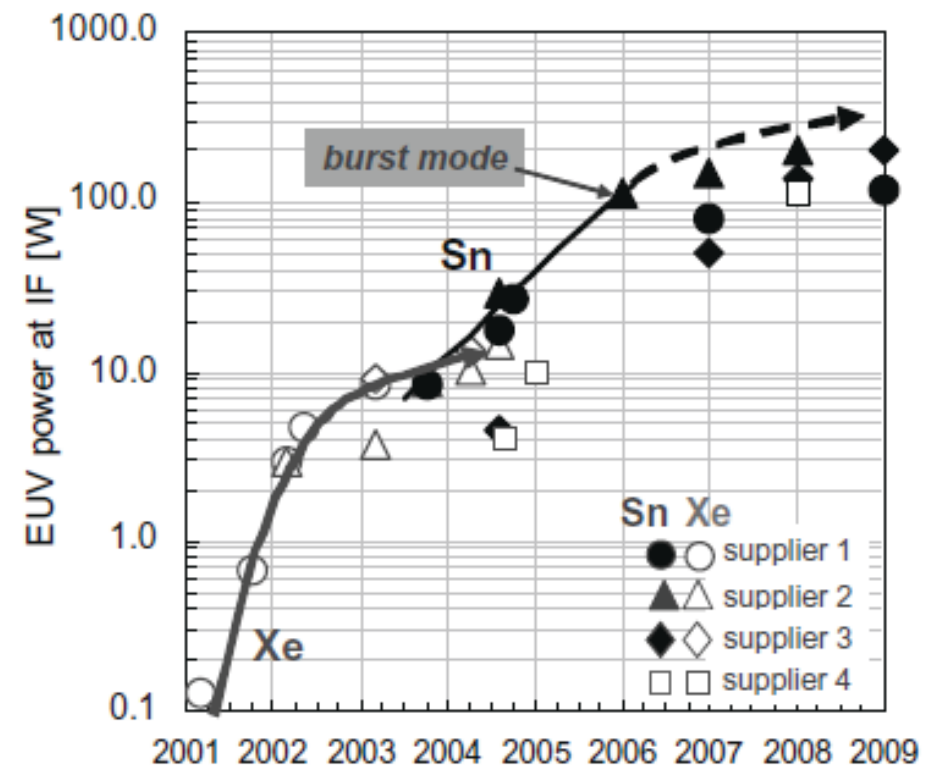

Since available power will determine the litho tool throughput, and Sn fueled sources are the most promising in terms of high power, ASML decided to incorporate a Sn discharge source on the AD-tool (see picture in Figure 5). Sn sources can provide the necessary photons for throughput, but they also generate debris which needs to be mitigated.

Hans Meiling et al., "First performance results of the ASML alpha demo tool," Proc. SPIE 6151, 615108 (2006) 


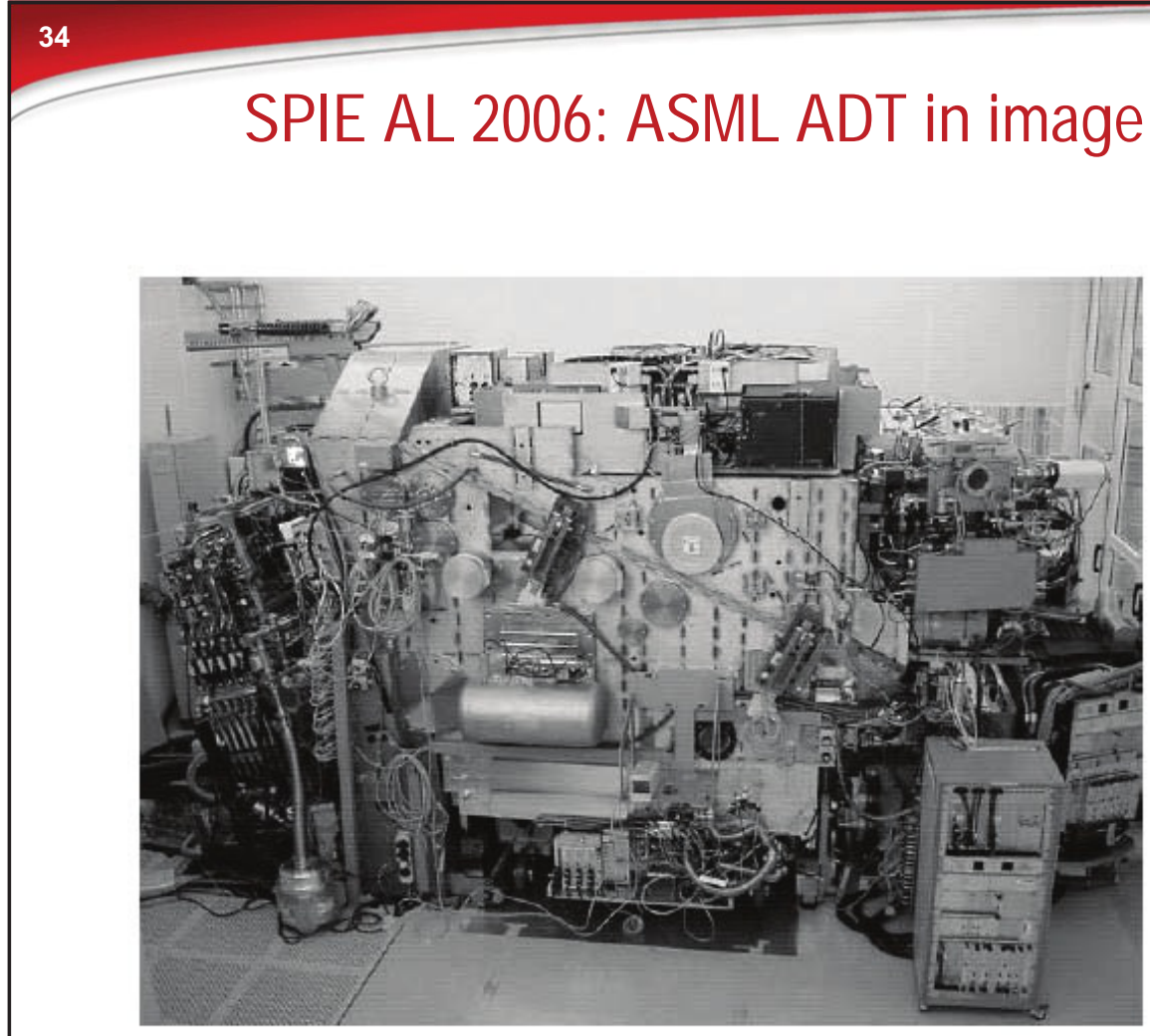

\begin{tabular}{|l|l|}
\hline & AD-tool \\
\hline$\lambda$ & $13.5 \mathrm{~nm}$ \\
\hline NA range & $0.15-0.25$ \\
\hline Field size & $26 \times 33 \mathrm{~mm}^{2}$ \\
\hline Wafer size & $300 \mathrm{~mm}$ \\
\hline Magnification & $4 \mathrm{x}$ \\
\hline Flare & $16 \%$ \\
\hline Dense L/S & $40 \mathrm{~nm}$ \\
\hline Isolated lines & $30 \mathrm{~nm}$ \\
\hline Iso/dense contact & $55 \mathrm{~nm}$ \\
\hline Overlay & $12 \mathrm{~nm}$ \\
\hline Throughput & $\sim 10 \mathrm{wph}$ \\
\hline
\end{tabular}

Hans Meiling et al., "First performance results of the ASML alpha demo tool," Proc. SPIE 6151, 615108 (2006) 


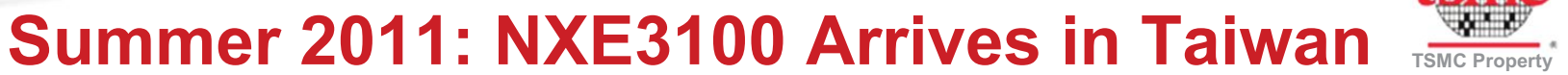

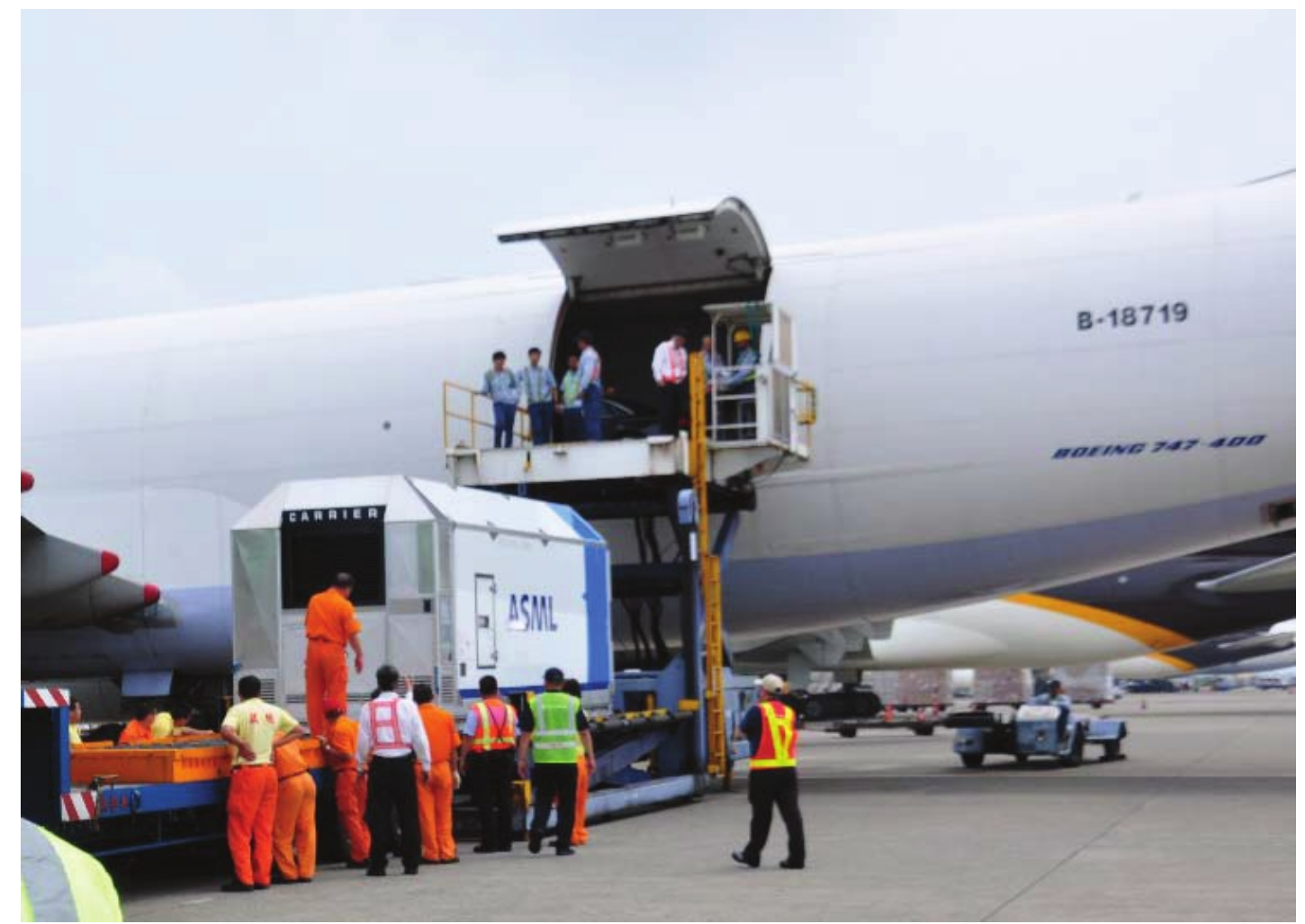

One of several scanner shipments arriving in Taiwan 


\section{1 \\ NXE3100: Installation Nearly Complete

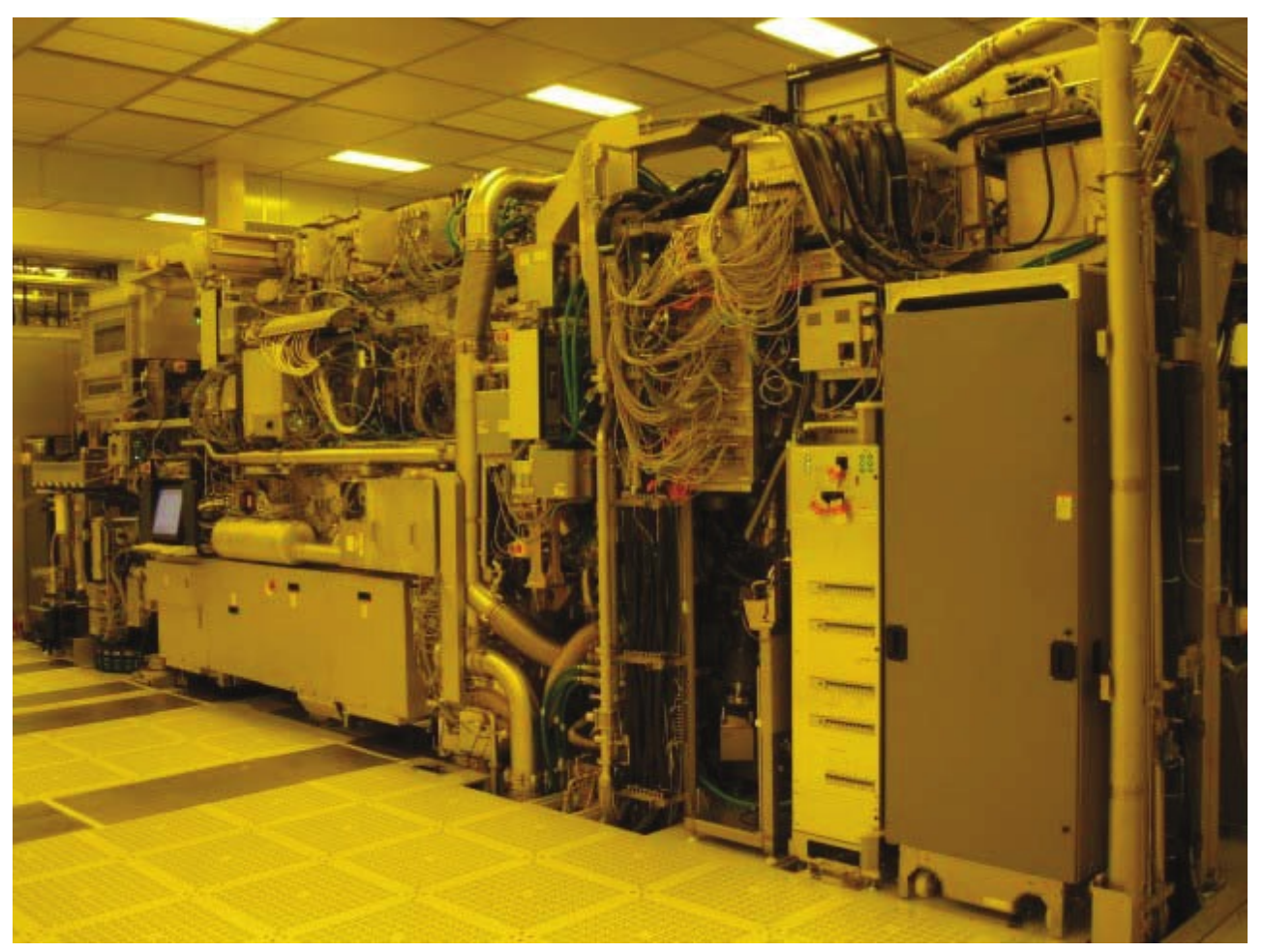

TSMC, October 2011 


\section{NXE3300: Installation Complete}

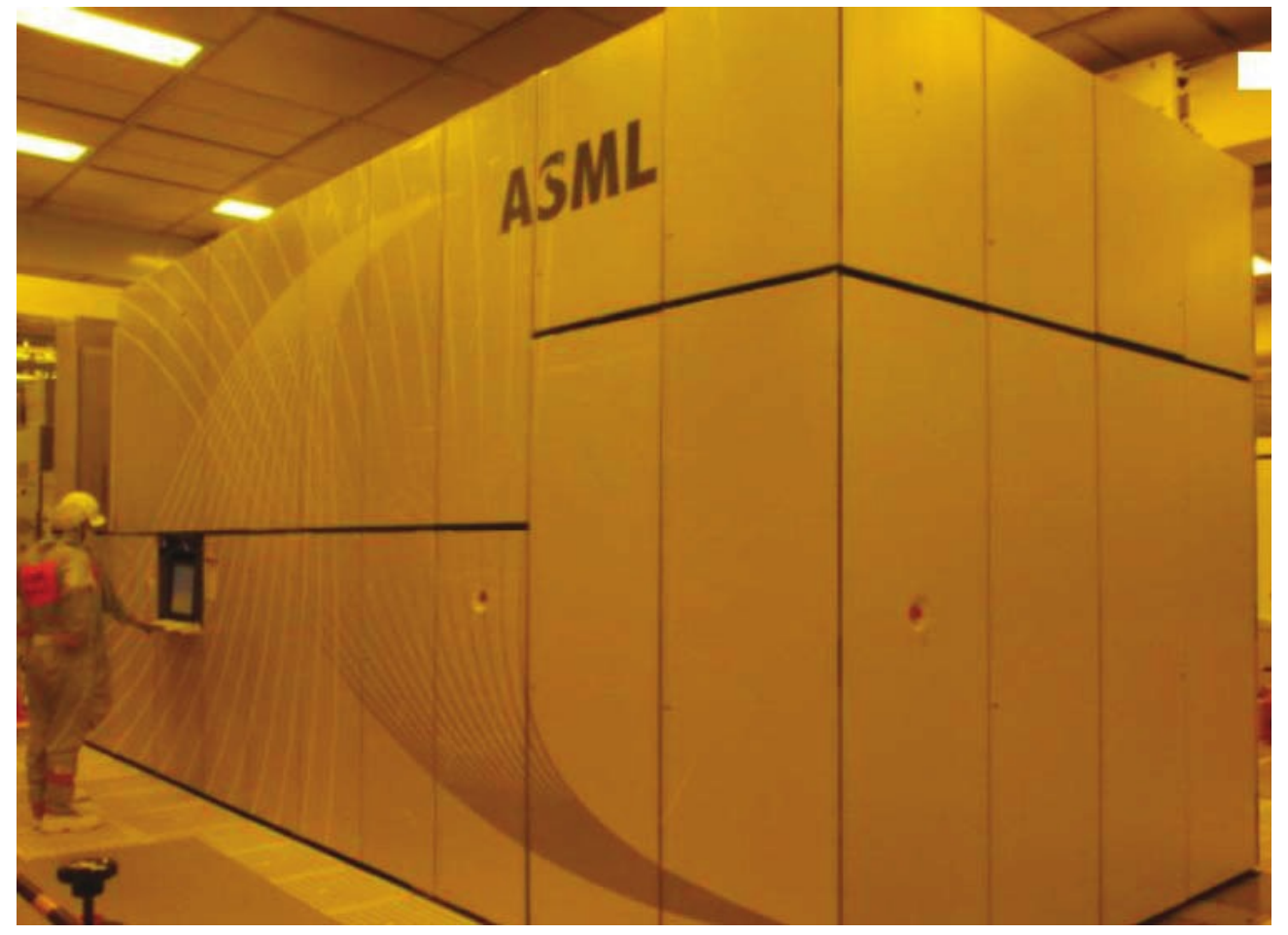

TSMC, October 2013 


\section{Mid-module of NXE3350 Arriving at TSMC}

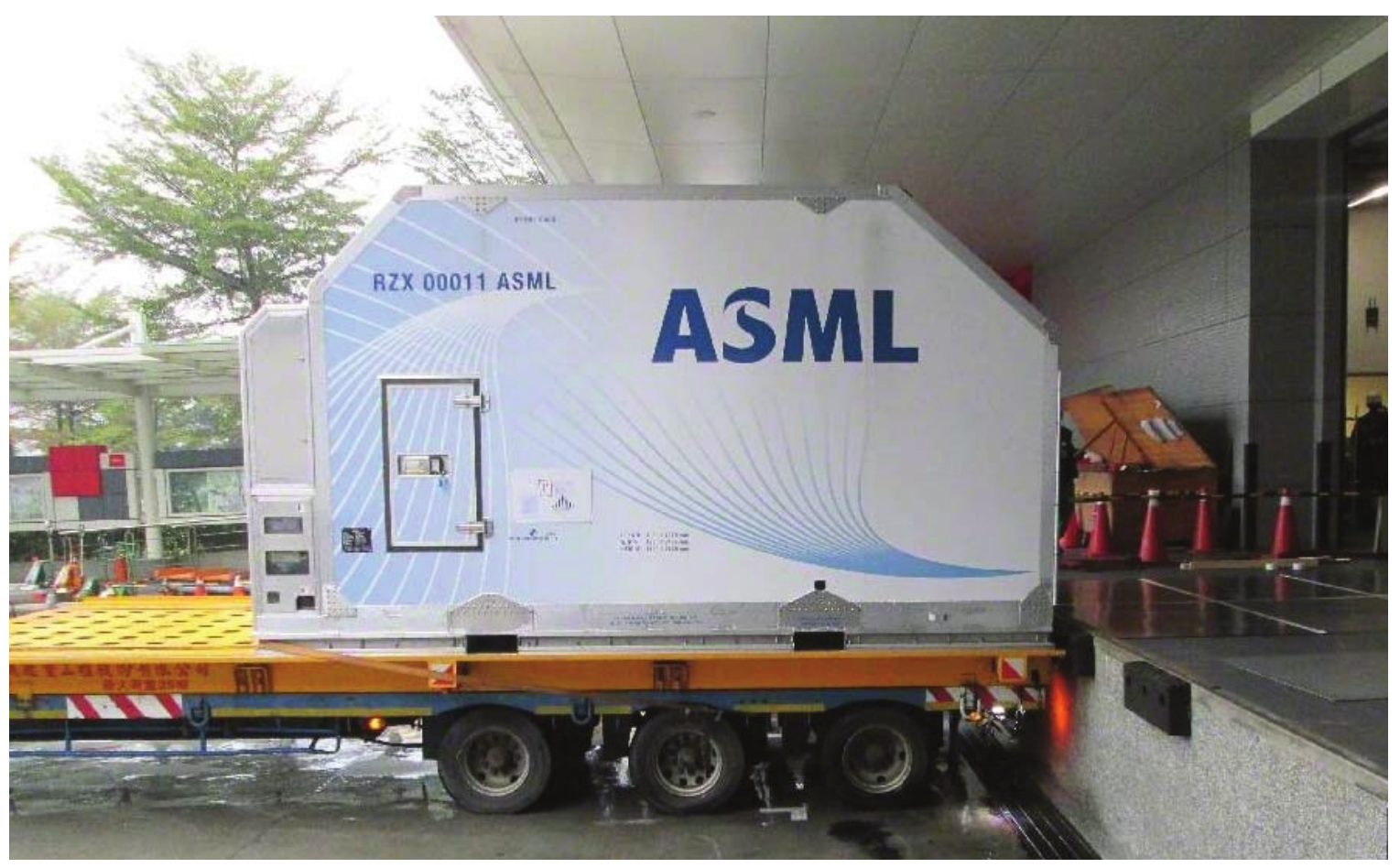

2016 


\section{EUV processing of metal layer of logic circuit}

Single Patterning by NXE3100

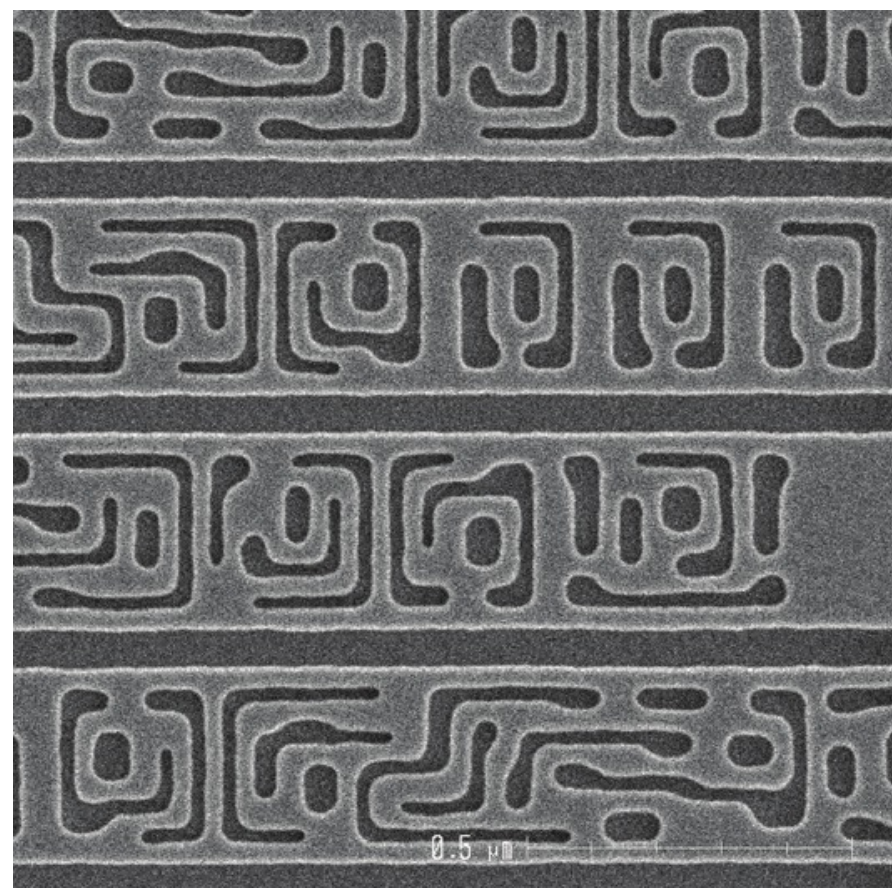

$$
\mathrm{P}=46 \mathrm{~nm} \text {; after hard-mask etch-through }
$$




\section{5}

\section{Via hole patterning: immersion vs. EUV}

Immersion lithography
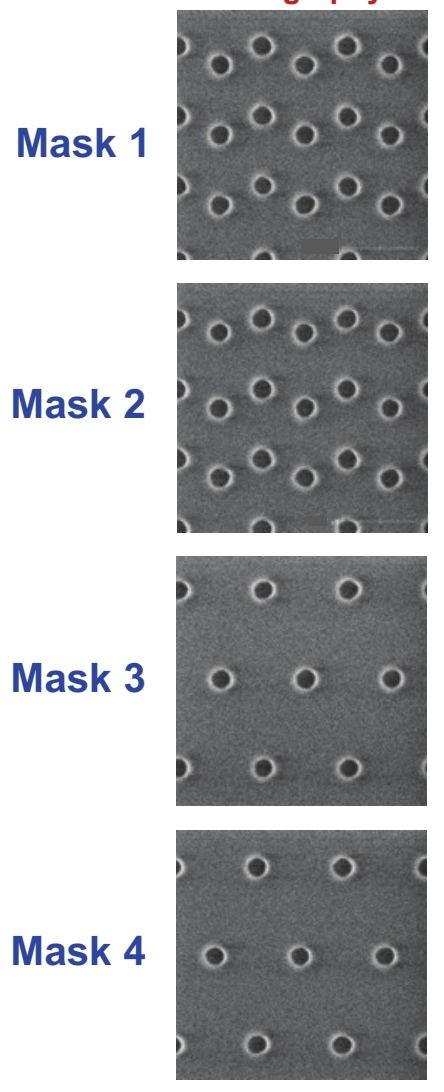

\section{Etch}
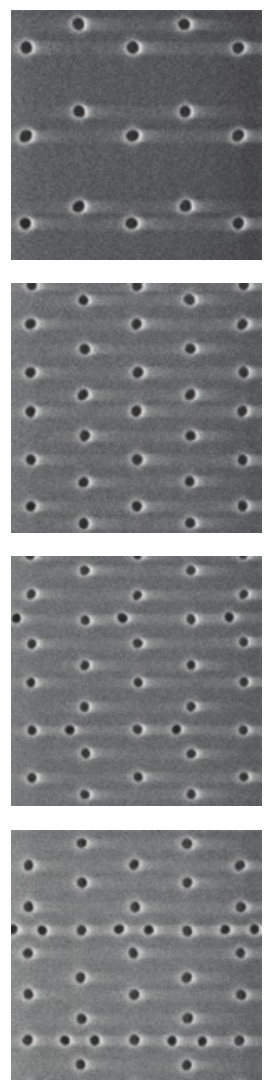

EUV single patterning

Combining patterns of all

4 immersion masks
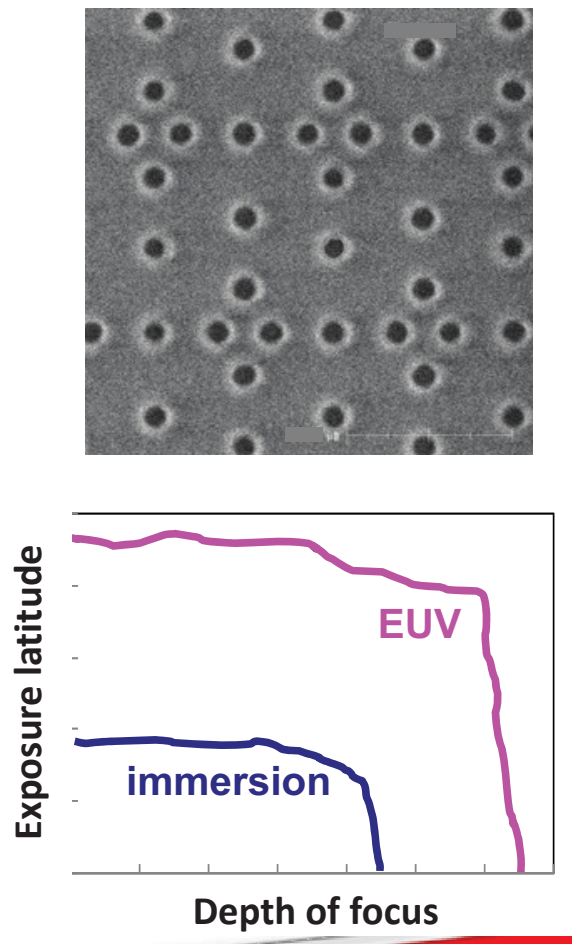


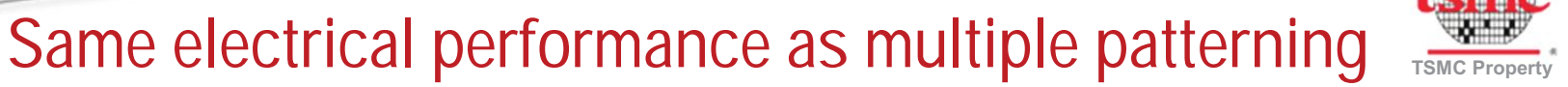
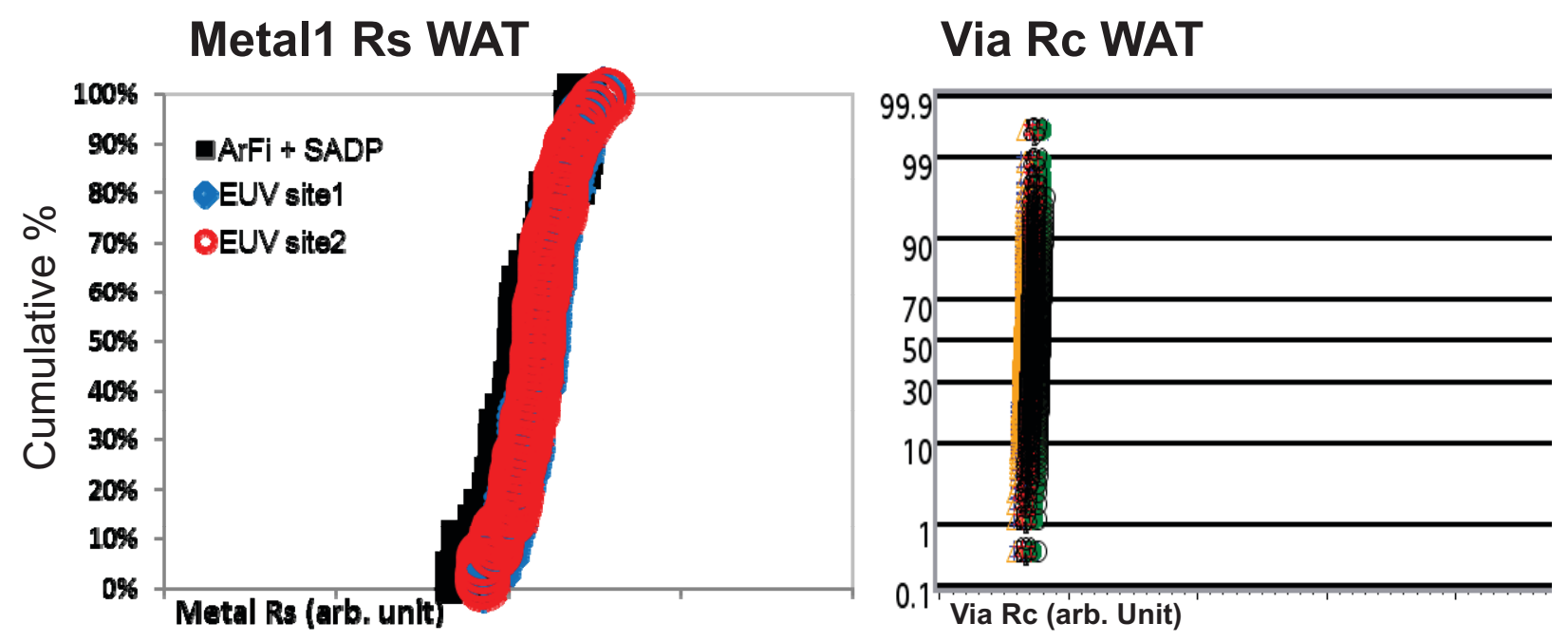

- Based on the same layout, CD target, and film stack, EUVL has achieved comparable electrical performance as the ArF immersion baseline 
Power of EUV is demonstrated by the following 2D structure

Designed pattern

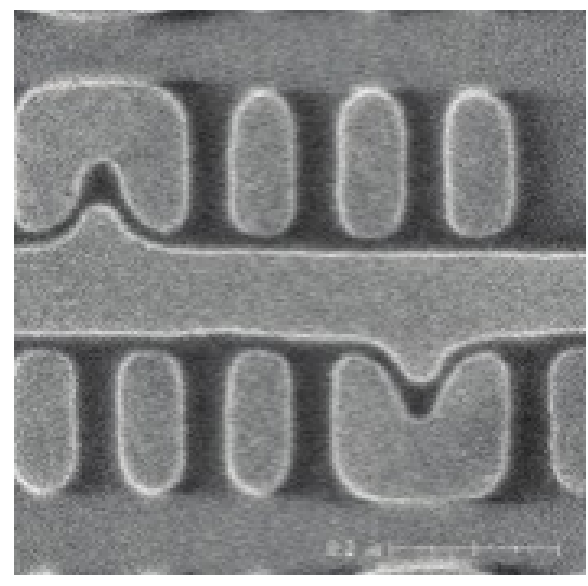

Immersion double patterning
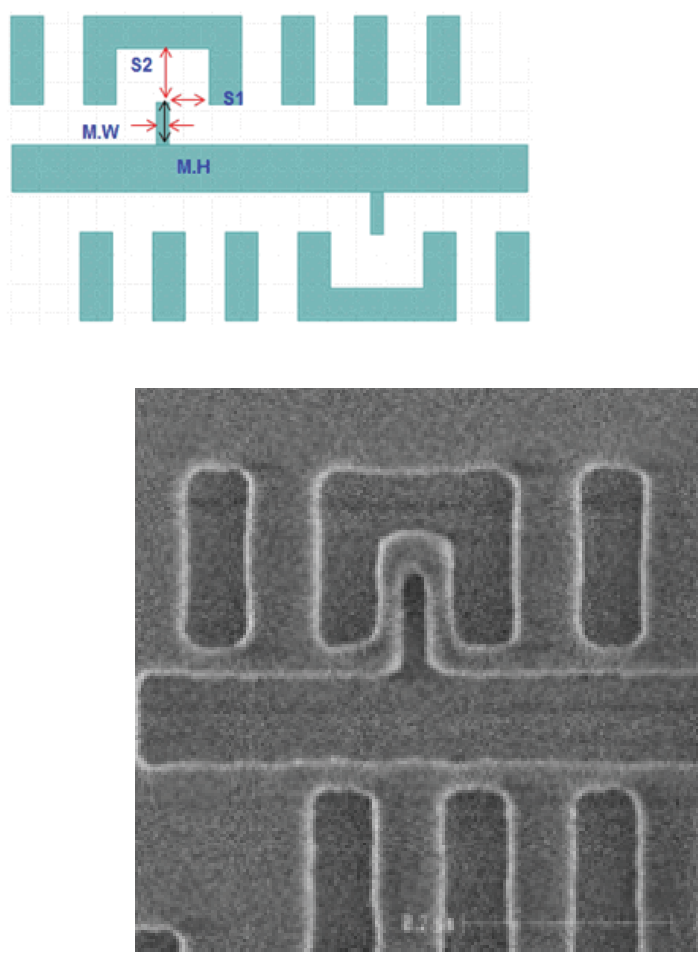

EUV single patterning 


\section{Progress on EUV source power}

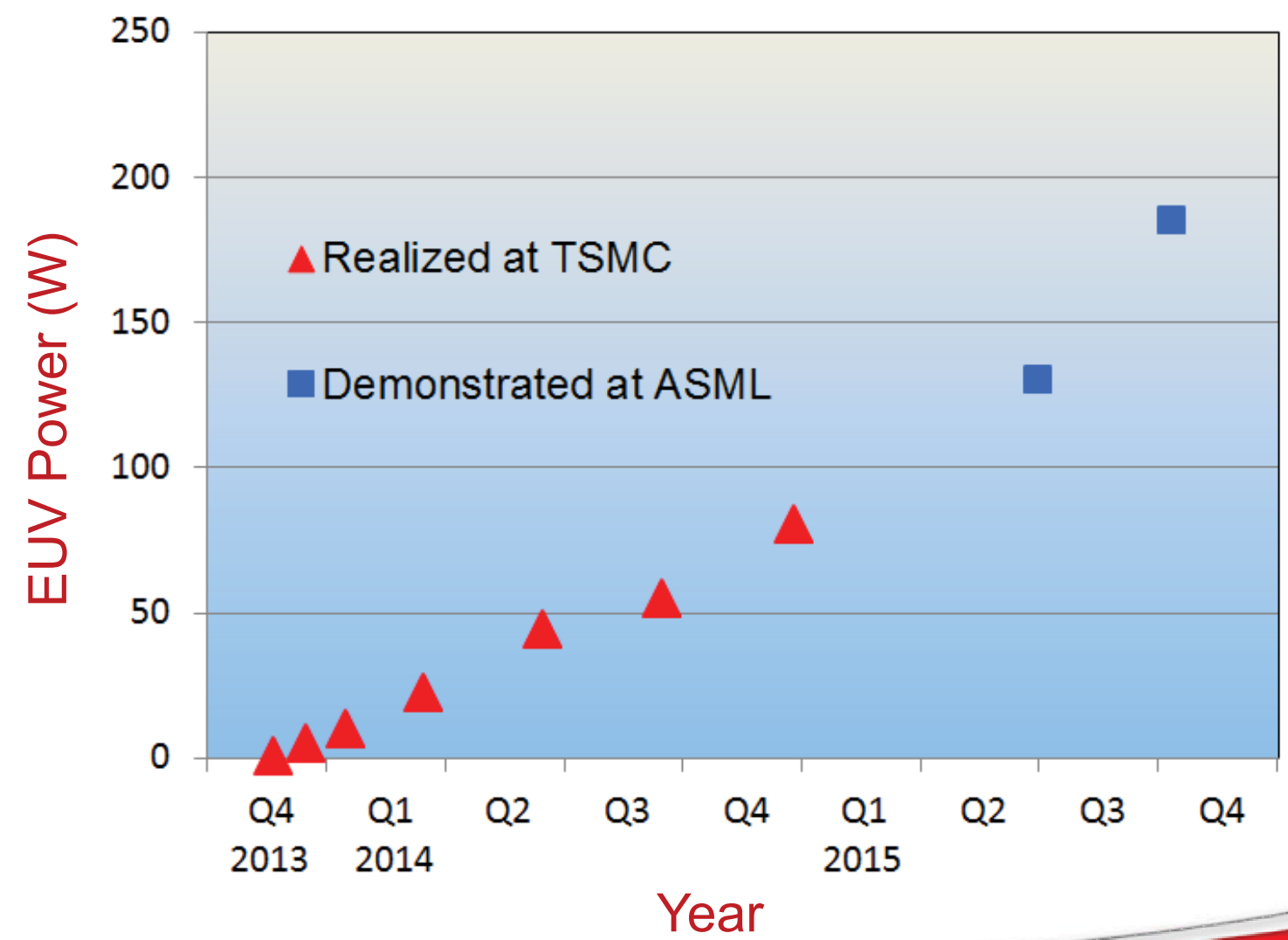




\section{W capability have been demonstrated at ASML}

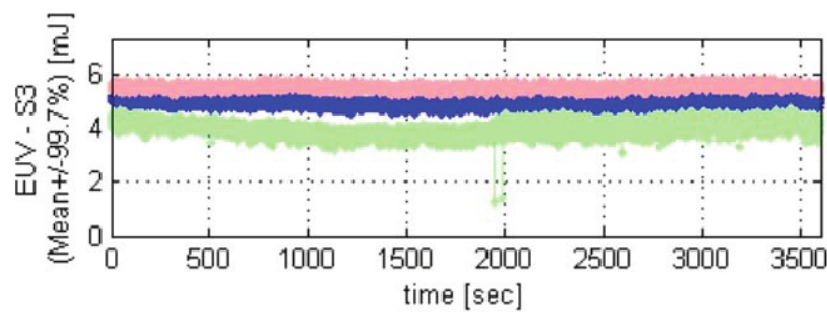

Mean pulse energy at IF: $\sim 5 \mathrm{~mJ}$

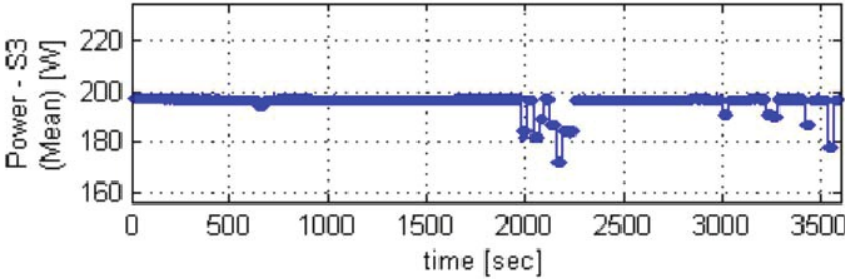

EUV power at IF: $200 \mathrm{~W}$

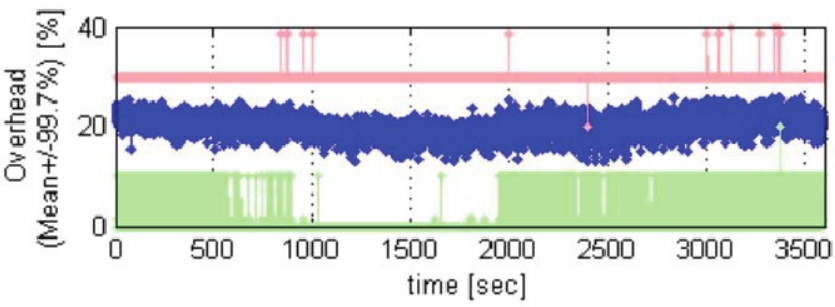

Energy control overhead: $\sim 20 \%$

\section{Courtesy of ASML}

Tuesday, 8:00 am (9776-10): EUV lithography performance for manufacturing: status and outlook Tuesday, 1:50 pm (9776-21): Advances in predictive plasma formation modelling 


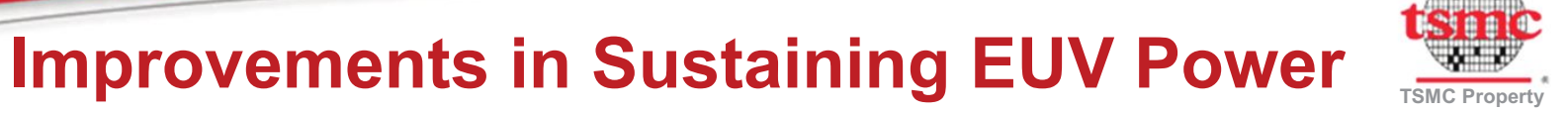 by maintaining collector cleanliness}

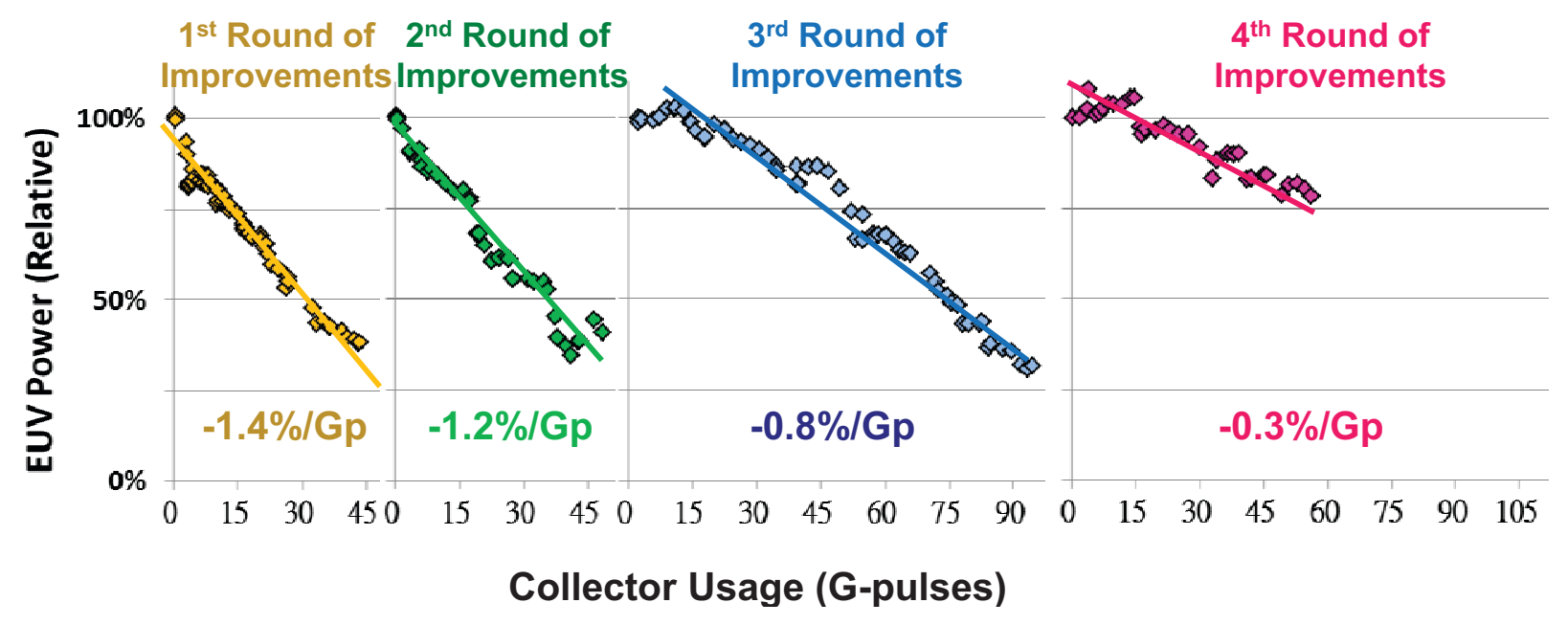




\section{Consecutive 4-week productivity on a NXE3300}

- Process conditions

- Wafers of various lot sizes with required dose, CD, and overlay

- 4-week-averaged WPD: 518 wafers

- Total wafers processed: 15040

- 4-week-averaged tool availability: $\mathbf{7 0 . 2} \%$

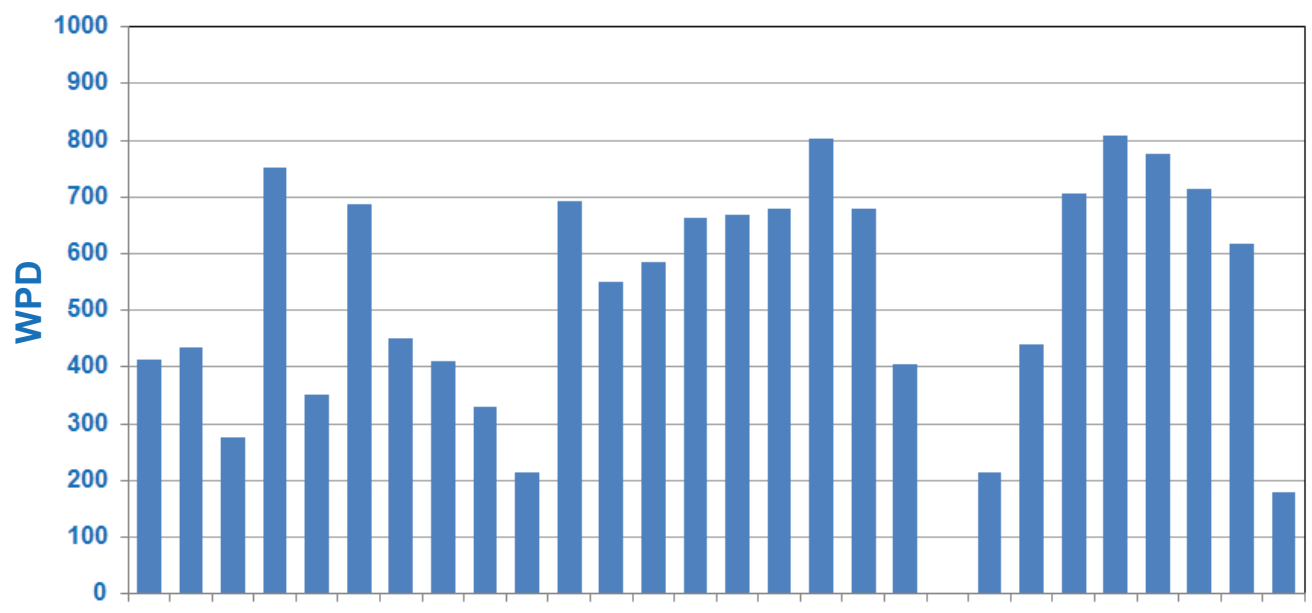

One bar represents a single day 


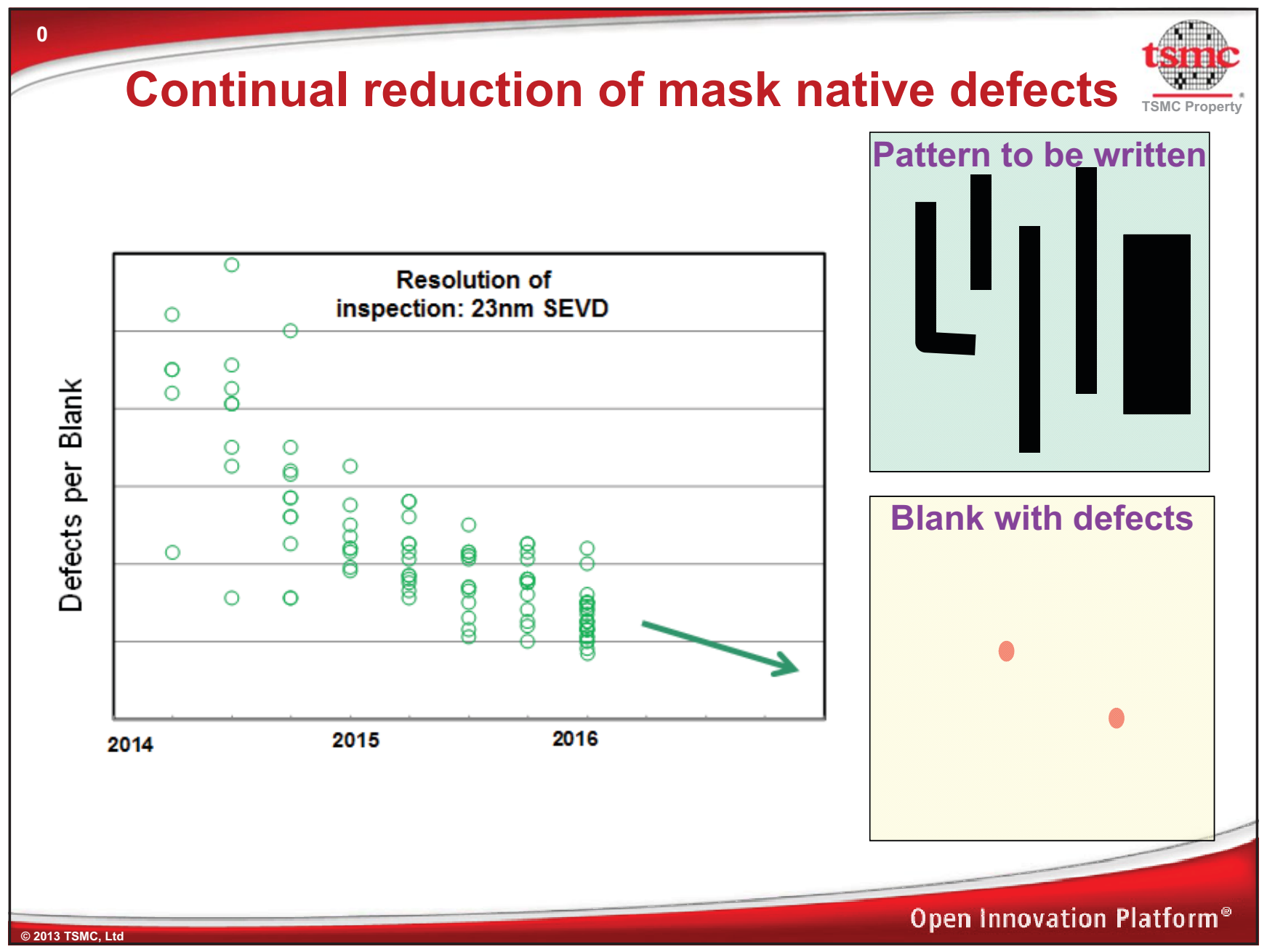

Proc. of SPIE Vol. $9776977632-47$ 


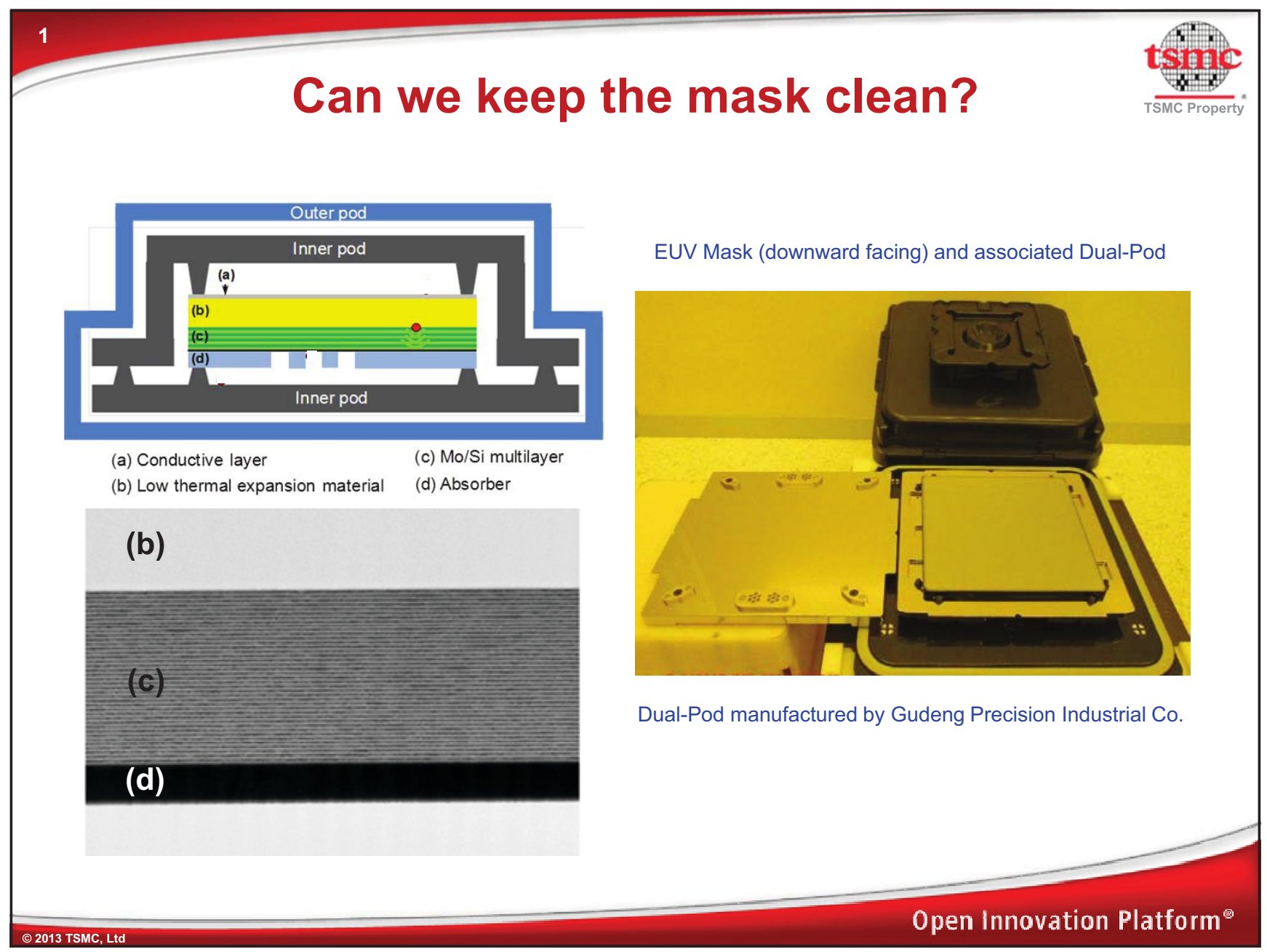

Proc. of SPIE Vol. $9776977632-48$ 


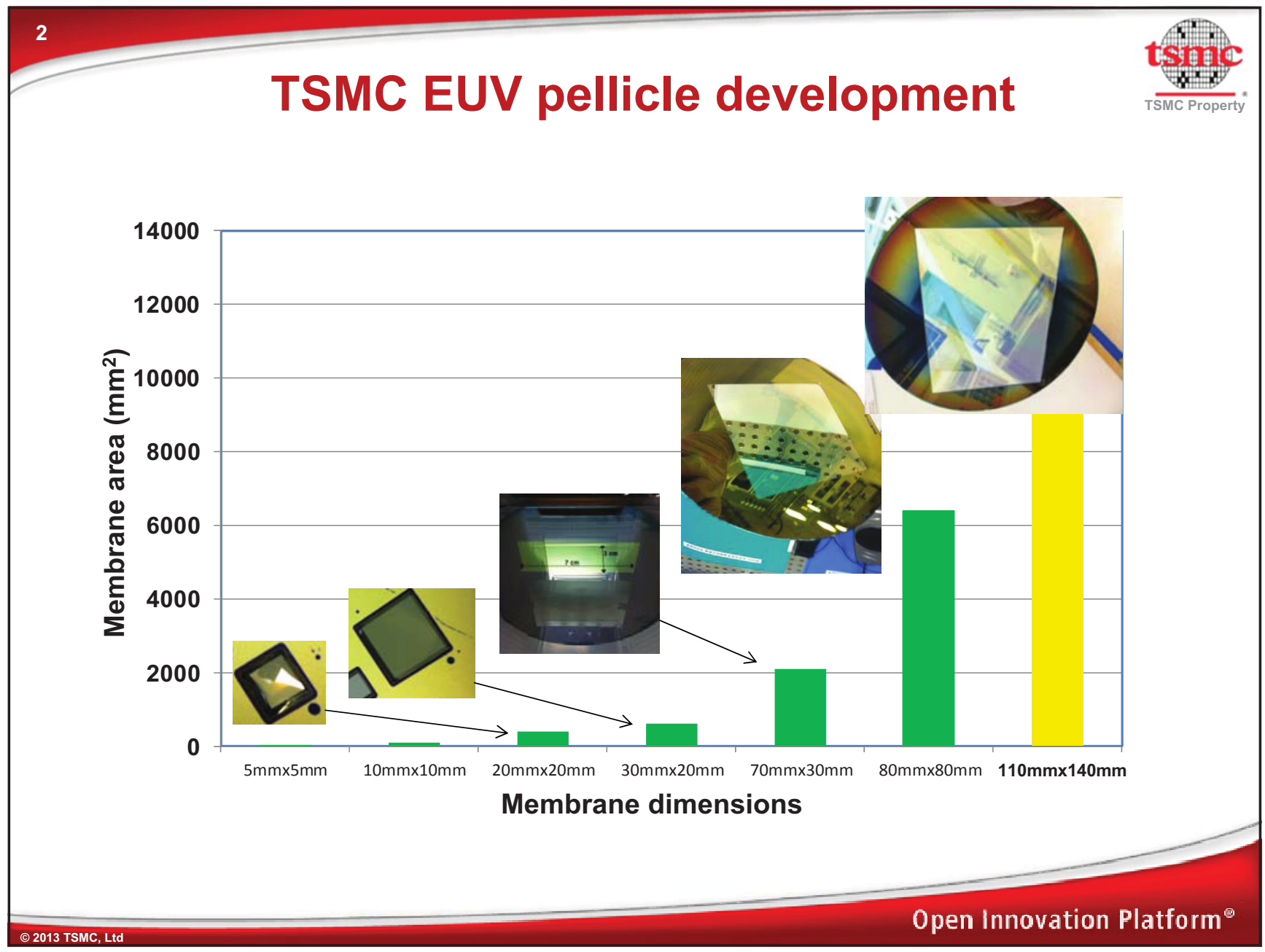

Proc. of SPIE Vol. $9776977632-49$

Downloaded From: https://www.spiedigitallibrary.org/conference-proceedings-of-spie on 26 Apr 2023 Terms of Use: https://www.spiedigitallibrary.org/terms-of-use 


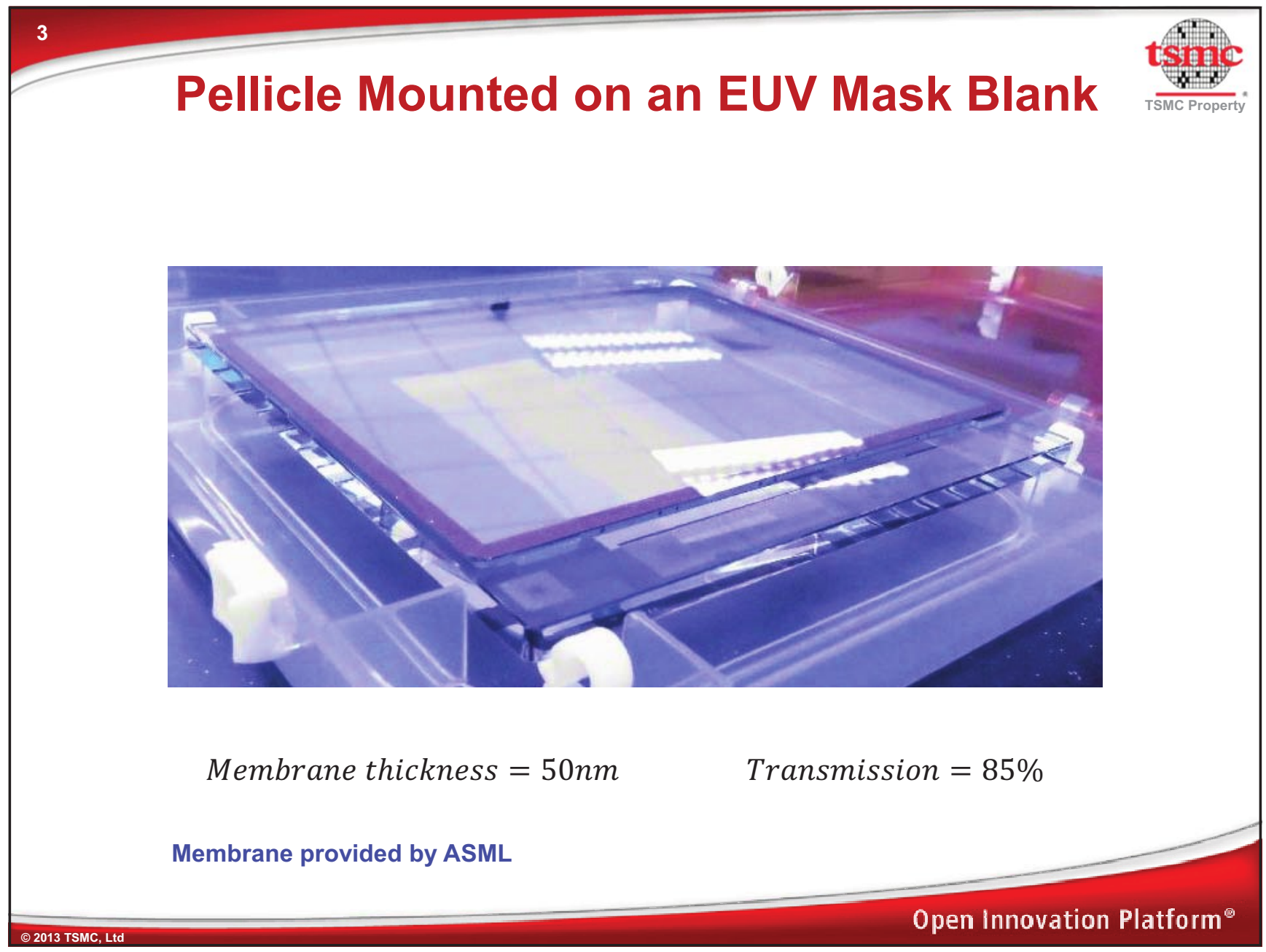

Proc. of SPIE Vol. $9776977632-50$ 


\section{Progress on EUV resist sensitivity and local CDU}

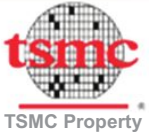

Sensitivity

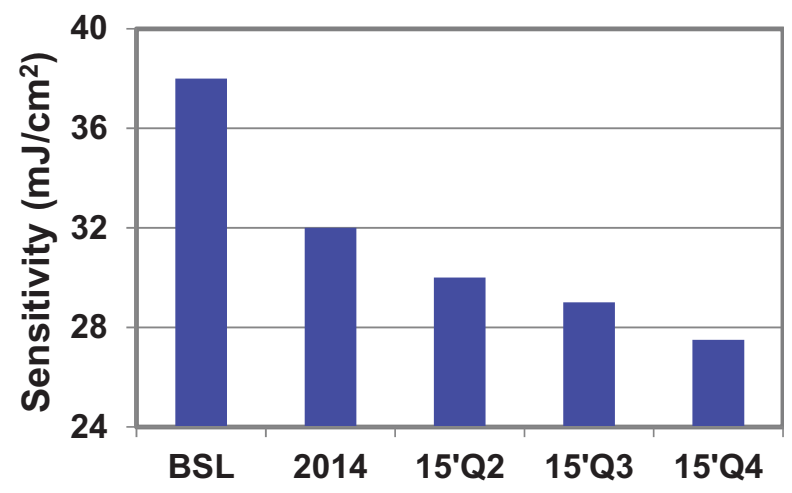

Local CDU

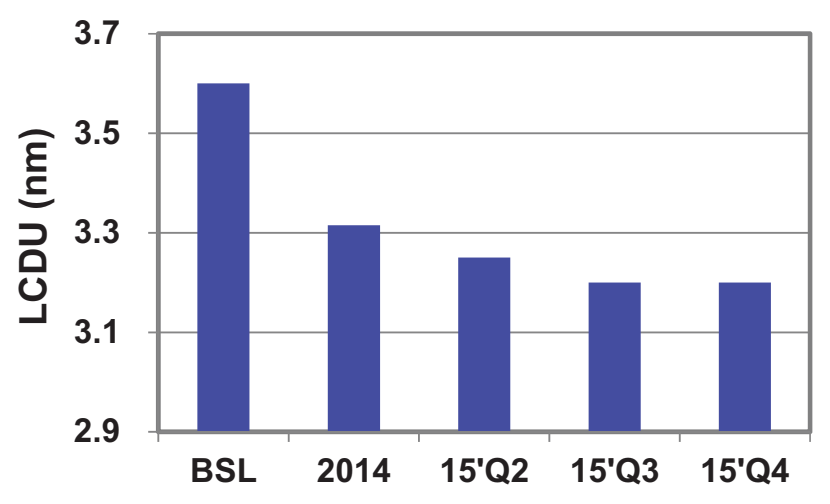

- Goal is to achieve $20 \mathrm{~mJ} / \mathrm{cm}^{2}$ sensitivity and $3 \mathrm{~nm}$ local CDU 


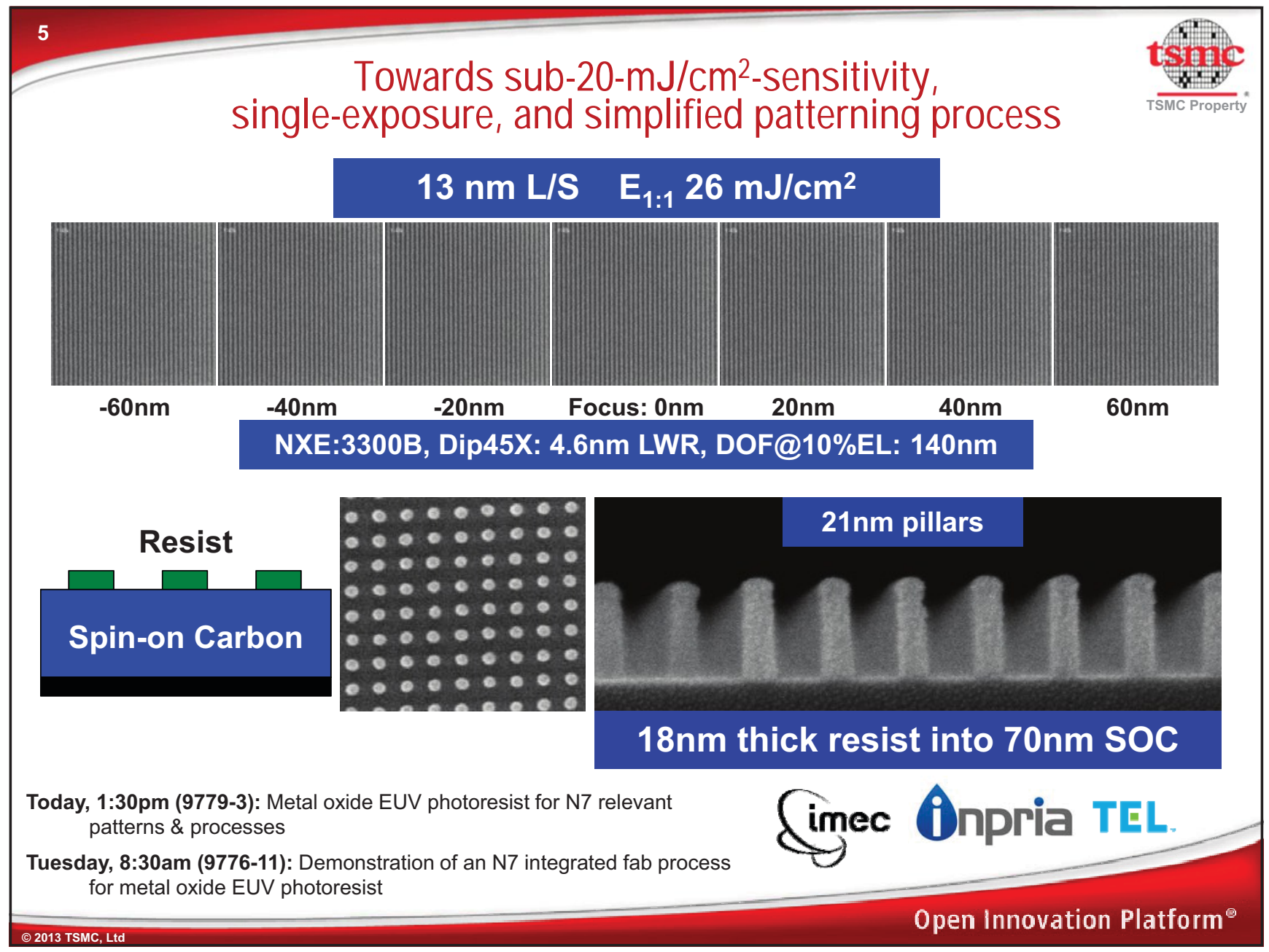




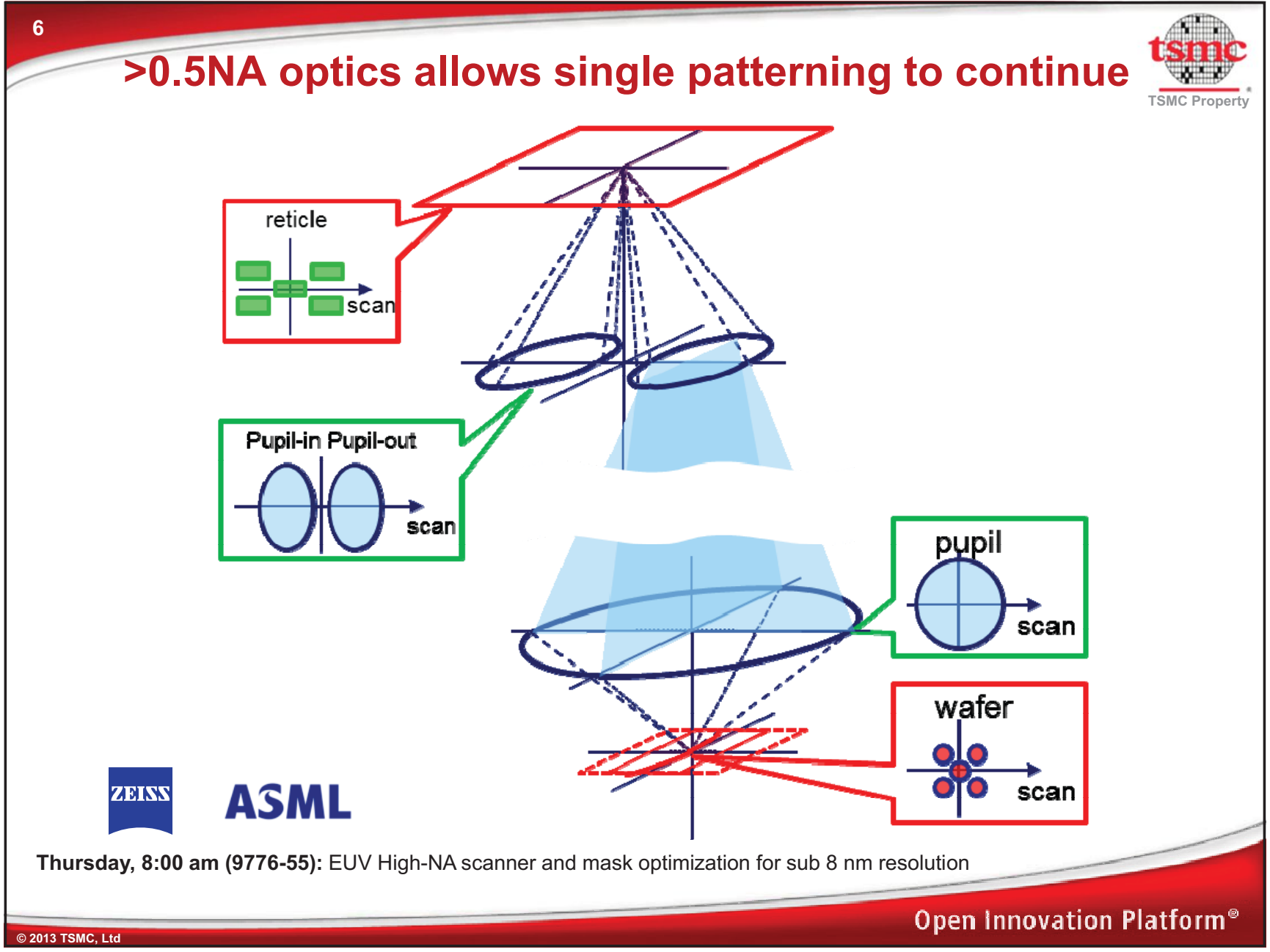

Proc. of SPIE Vol. $9776977632-53$

Downloaded From: https://www.spiedigitallibrary.org/conference-proceedings-of-spie on 26 Apr 2023 Terms of Use: https://www.spiedigitallibrary.org/terms-of-use 


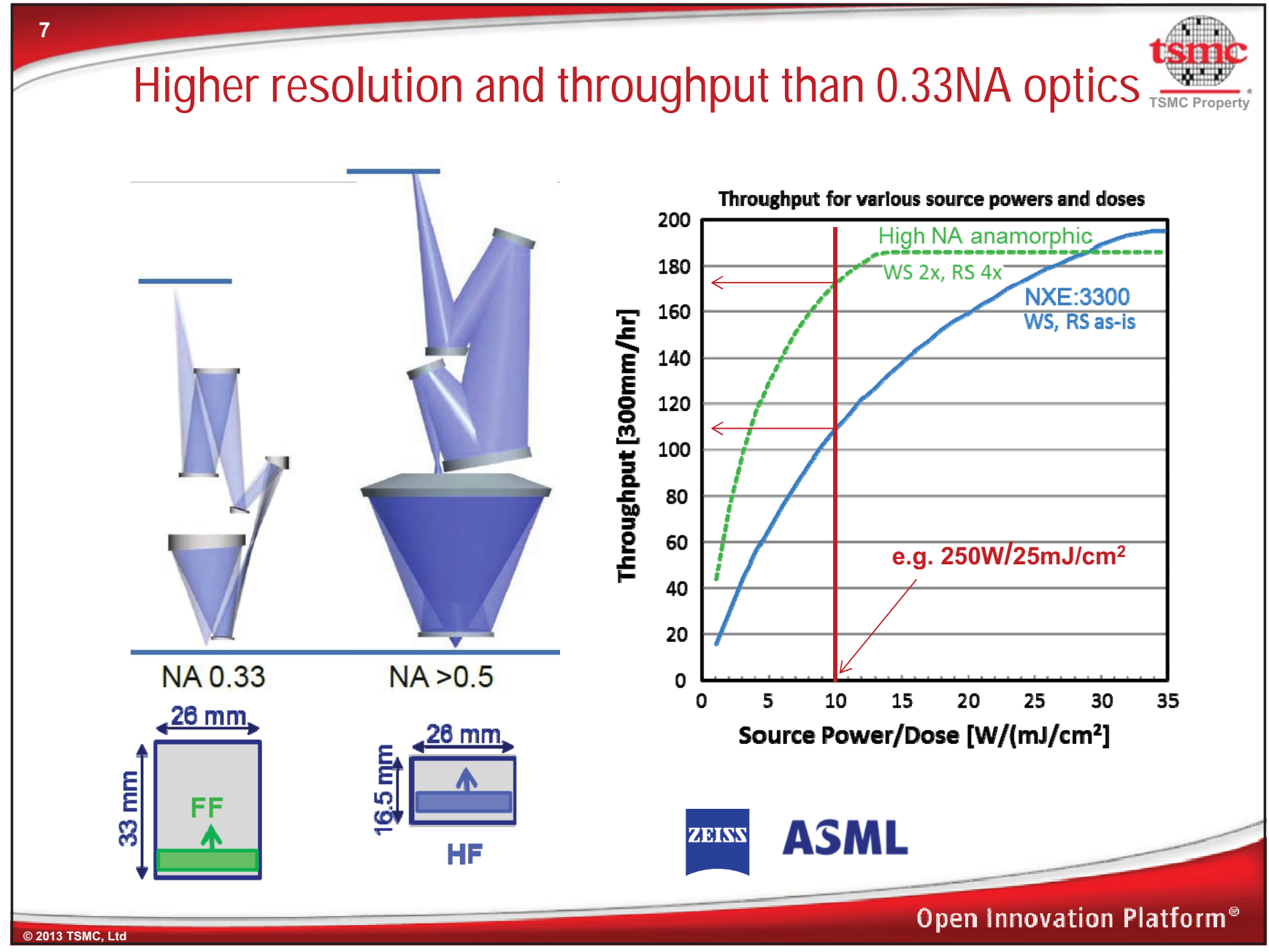

Proc. of SPIE Vol. $9776977632-54$ 


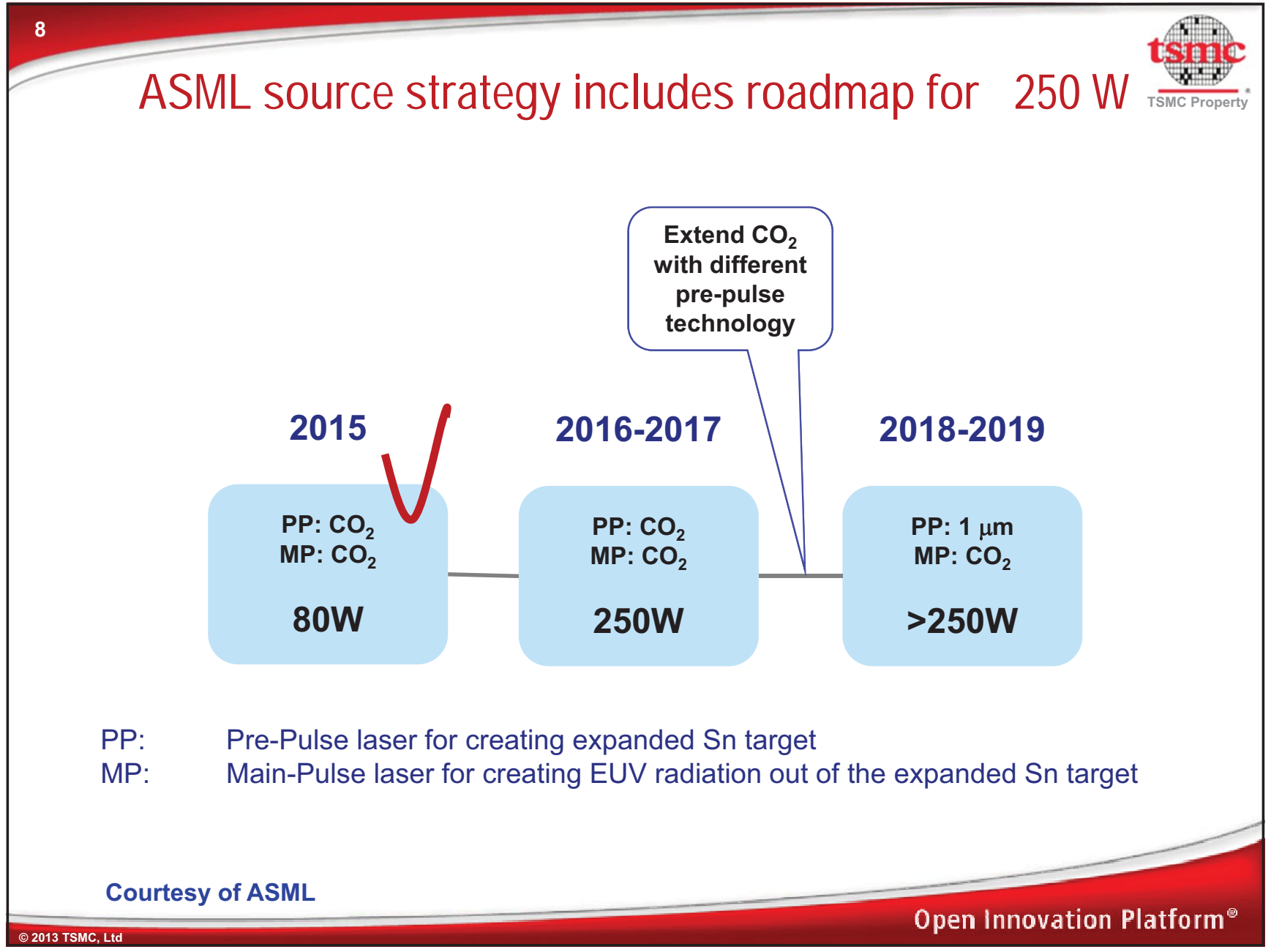

Proc. of SPIE Vol. $9776977632-55$ 


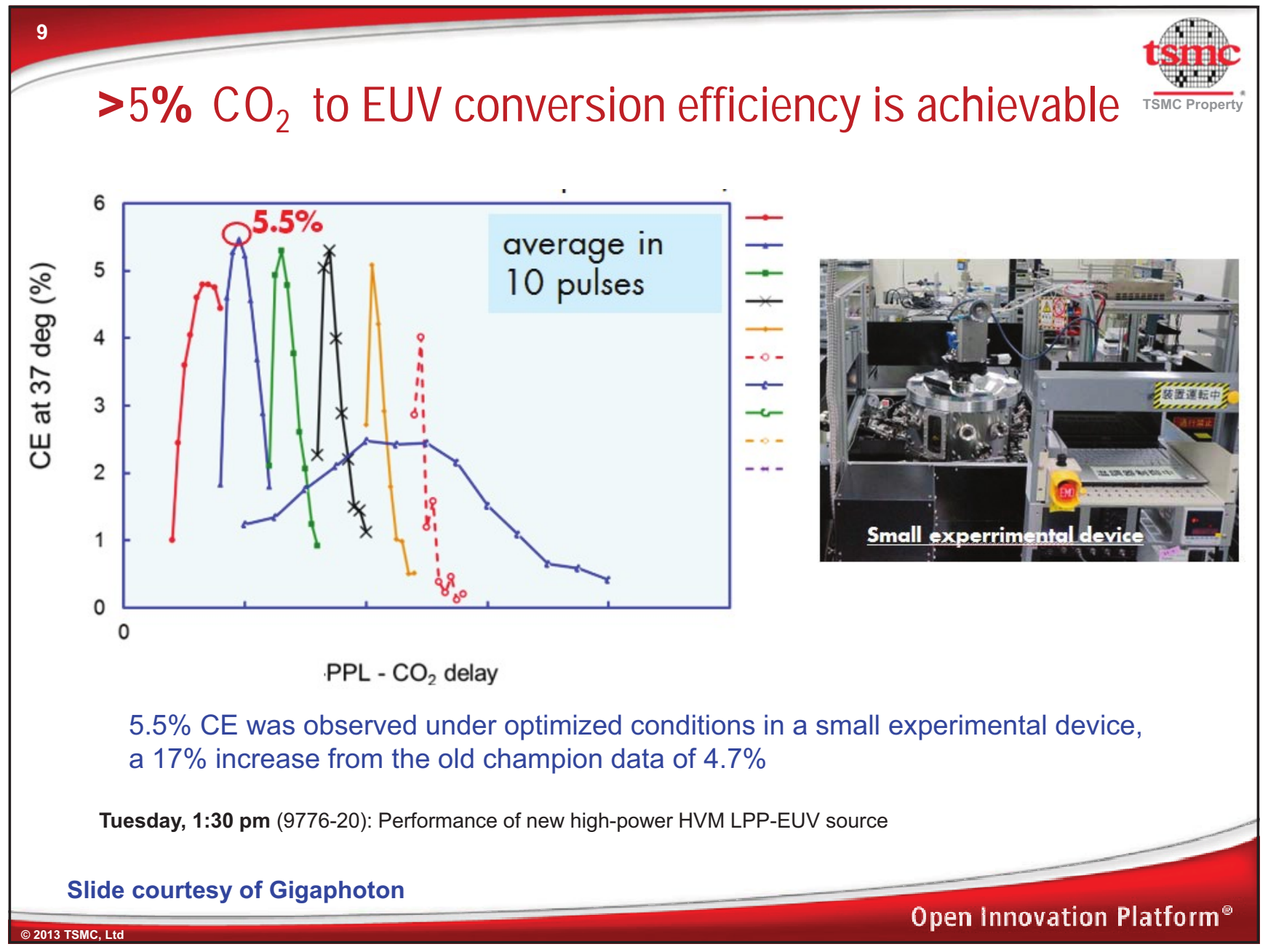




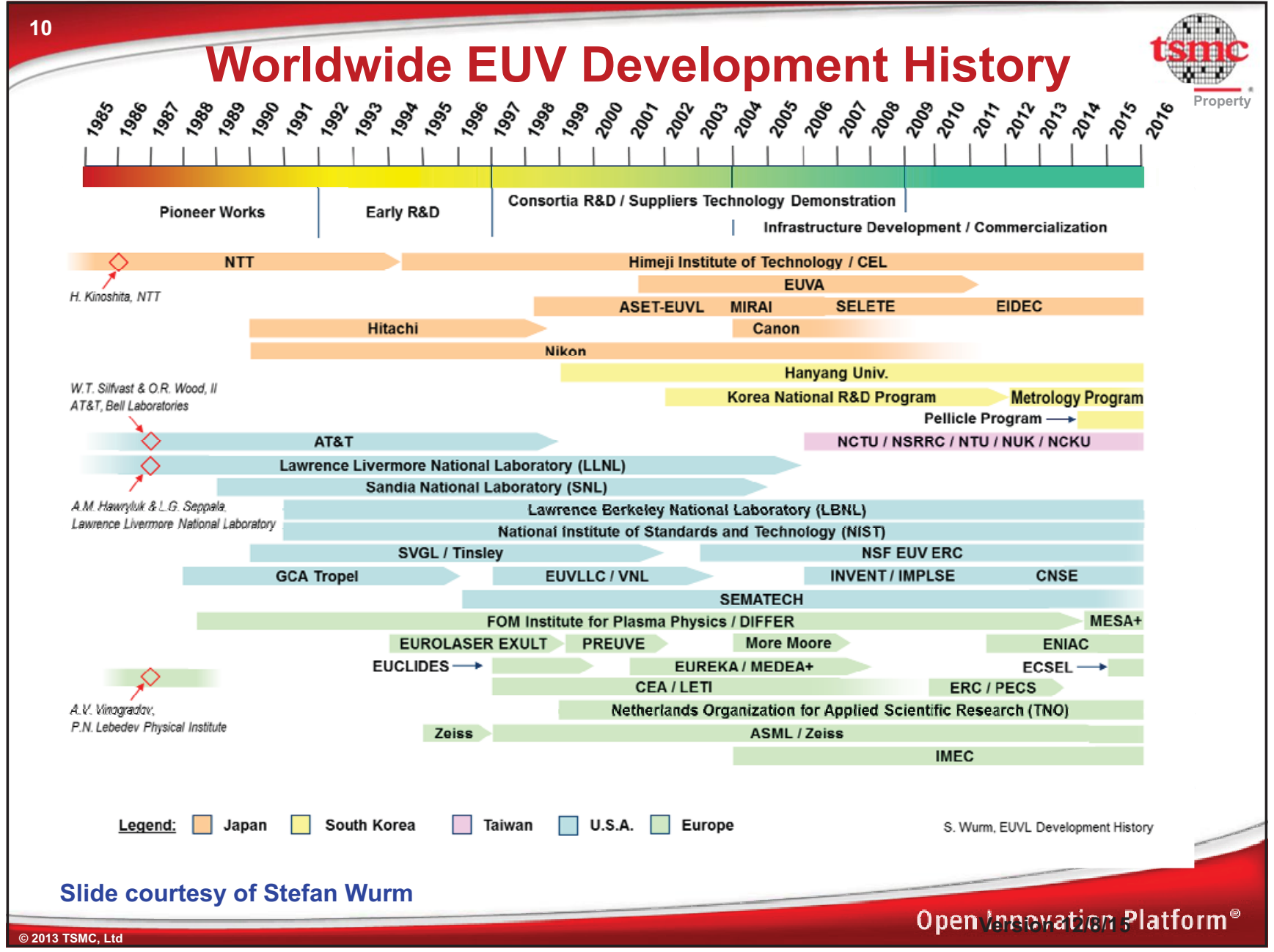




\section{Summary}

- It is extremely difficult to unseat an existing technology, especially when it still has headroom for incremental improvements and tweaks

- When you believe in your vision, you have to stick to your belief against complacency, skepticism, prejudices, and sometimes mockeries

- Technologists - continual and unabated innovation

- Executives - appropriation of massive amounts of resources

- Substantial progress has been made in the past 10 years in the development of infrastructure for EUVL

- Need this community to continue to work together, innovate, and finish the last mile in the development of EUVL for HVM 


\section{Acknowledgment}

- Obert Wood, Nat Ceglio, Andy Hawryluk, and John Carruthers for sharing knowledge and material on the early days of EUVL

- Hiroo Kinoshita for making available his presentation material on EUVL and for clarifying details in his initial experiments

- Stefan Wurm for clarifying many topics regarding EUV LLC

- Vivek Bakshi for fruitful discussions on the choice of the $13.5 \mathrm{~nm}$ wavelength

- Our R\&D team for their full dedication in making EUVL a reality in HVM

- TSMC's management for their full and continual support in the development of EUVL

- The entire EUV community - in our common belief that EUV is the choice for the continuation of Moore's law

- Exposure tools and optics and light sources; Masks and blanks and pellicles and infrastructure; Resists, etc. 